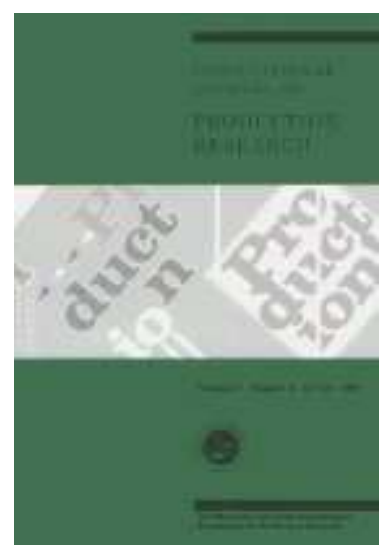

\title{
Determination of angular fields outside low and high collisions to mill free-form surfaces on 5-axis CNC Machines
}

\begin{tabular}{|r|l|}
\hline Journal: & International Journal of Production Research \\
\hline Manuscript ID: & TPRS-2010-IJPR-0224.R2 \\
\hline Manuscript Type: & Original Manuscript \\
\hline $\begin{array}{r}\text { Date Submitted by the } \\
\text { Author: }\end{array}$ & 28 -Sep-2010 \\
\hline Complete List of Authors: & $\begin{array}{l}\text { Gilles, Patrick; Université paul Sabatier, Institut Clément Ader } \\
\text { Senatore, Johanna; Université Paul Sabatier, Institut Clement Ader } \\
\text { Segonds, Stéphane; Université Paul Sabatier, Institut Clément Ader } \\
\text { Monies, Frederic; Université Paul Sabatier, Institut Clément Ader } \\
\text { Rubio, Walter; Université Paul Sabatier, Institut Clément Ader }\end{array}$ \\
\hline Keywords: & CAM, CNC MACHINING, SCULPTURED SURFACES \\
\hline Keywords (user): & 5 axis machining, tool positionning \\
\hline & \multicolumn{2}{|c}{} \\
\hline
\end{tabular}

\section{SCHOLARONE \\ Manuscripts}




\title{
Determination of angular fields outside low and high collisions to mill free-form surfaces on 5-axis CNC Machines
}

\author{
P. Gilles, J. Senatore, S. Segonds, F. Monies*, W. Rubio \\ *corresponding author : Tel. +33 561557701 \\ E-mail address : monies@lgmt.ups-tlse.fr \\ Institut Clément Ader laboratory, Université Paul Sabatier, 118 route de Narbonne, bat.3R1, \\ 31062 Toulouse cedex 4, France
}

P. Gilles : $\quad$ Tel. +33561557748

E-mail address : gilles@1gmt.ups-tlse.fr

J. Senatore : Tel. +33561557701

E-mail address : senatore@lgmt.ups-tlse.fr

S. Segonds : Tel. +33561557317

E-mail address : ssegonds@cict.fr

W. Rubio: Tel. +33 561558824

E-mail address : rubio@cict.fr 


\title{
Determination of angular fields outside low and high collisions to mill free-form surfaces on 5-axis CNC Machines
}

\begin{abstract}
The present article addresses positioning of a flat end milling cutter to ensure avoidance of local and global interference. The activity concerned is end milling of parts modelled by freeform surfaces on 5-axis Numerical Control machines.

The tool positioning defined here uses two corrective angles and thus takes full advantage of all the possibilities for 5-axis machine movement.

Local interference is cancelled out from a set of points defining the domain of the surface in collision with the cutter and an angular solution domain is proposed to orient the cutter. Global interference is resolved using a set of points; here too, a collision-free angular domain is defined. To obtain a collision-free tool, the two previously mentioned angular domains are superimposed. An additional corrective method is defined if no solution is found using the previous method. Finally, positioning free from local and global interference is obtained. The method was coded and positioning simulations were used to validate the approach's effectiveness.
\end{abstract}

Keywords : 5 axis machining, local collision, global collision, tool positioning

\section{INTRODUCTION}

To produce complex shaped workpieces on 5-axis CNC machines, collisions between the cutter and the surfaces modelling the workpiece need to be detected so as then to correct the cutter positioning to ensure avoidance.

There are two types of collision: local collisions (or gouging) and global collisions (cf. figure 1). The term local collision (or local interference) will be used when the end of the cutter interferes with the surface to be machined. Meanwhile, global collision refers to the case where the side of the cutter or the tool-holder interferes with one or more of the non-machined surfaces.

CAM software can be used to detect global collisions but does not always give a solution to position the tool; in the zones of the workpiece where a global collision is detected locally, the program leaves the zone un-machined. The aim of the present study is to offer the operator optimal management of collisions. This will lead to greater removal of material from the workpiece using the same cutter.

The present work follows on from a situation where the cutter is assumed to be in collision, with the latter being capable of being detected by one of the existing methods to be found in the literature (Bergen 1997, Klosowski 1998, Tang et al. 2007).

Figure 1. Local and global collisions 
A methodology will be defined to ensure cutter-surface compatibility by taking the following two aspects into account:

- Local aspect relating to the area near the cutter contact zone on the surface and to the rear of the cutter.

- Aspect relating to the entire surface of the cutter; this involves checking that there is no intersection outside the active working zone of the cutter.

This paper is structured as follows. Section 2 introduces related work on existing corrective methods. Section 3 discusses different types of collision and the correction methods adopted in the present article.

Several application examples are given in Section 4. The last section concludes.

\section{EXISTING CORRECTIVE METHODS}

\subsection{LOCAL CORRECTIONS}

There are many end positioning strategies to be found in the literature for flat ended cutters and torus milling cutters. Most studies adopt a reference local to the machined surface, whose origin is defined at the cutter-surface $\mathbf{P}_{\mathbf{C}}$ point of contact located at the periphery of the cutter. This reference is related,

$\checkmark$ either to the direction of milling and defined by $\left(\mathbf{P}_{\mathbf{C}}, \mathbf{t}, \mathbf{b}, \mathbf{n}\right)$, where $\mathbf{n}$ is the normal to the surface, $\mathbf{t}$ is the tangent to the surface in the machining direction and $\mathbf{b}=\mathbf{n} \wedge \mathbf{t}$,

$\checkmark$ or to the local curvatures of the surface and then defined by $\left(\mathbf{P}_{\mathrm{C}}, \mathbf{e}_{1}, \mathbf{e}_{2}, \mathbf{n}\right)$ in the case of an approach by differential geometry, and where $\mathbf{e}_{\mathbf{1}}$ and $\mathbf{e}_{\mathbf{2}}$ are two normed vectors, oriented in accordance with the principal directions.

Working from an initial position of the cutter where its axis is collinear with the normal to the surface at $\mathbf{P}_{\mathbf{C}}$, the authors use either one angle or two angles for correction to orient the cutter axis. Positioning operations with two correction angles allow local interference to be eliminated with the aim of optimising the cutter position. Works using the local geometry of the surface have been conducted (Wang et al. 1993, Lee and Ji 1997, Chen et al. 2002, Jensen et al. 2002, Rao and Sarma 2000, Wang and Tang 2008). Here, the general idea was to compare the effective radius of the cutter facing the surface curvature radius. The drawback with these methods is that they come unstuck if the surface shows major changes in curvature. Other methods use a set of points belonging to the part of the surface in interference with the cutter to allow the latter to be disengaged (Rubio et al. 1998, Redonnet et al. 2000, Gray et al. 2005). These methods can be applied to any shape of surface.

\subsection{GLOBAL CORRECTIONS}

Some methods propose a cutter disengagement along a given direction through successive tests until the cutter is no longer in collision (Takeuchi et al. 1995). The major drawback with these methods is that if the cutter orientation is not acceptable technologically, they offer no other solutions. Alternative methods use notions of visibility (Wang and Tang 2008, Elber and Zussman 1998); here, the visibility of a surface or surface element is defined by the set of possible approach directions. The cutter is modelled by an axis and the surfaces tested in collision have to be offset; it then becomes difficult to consider the cutter and the cutter holder in managing collisions. To handle the problem of visibility, some researchers have used the Gauss map (or G-Map) concept, that is the set of normals of the surface mapped as a unit sphere. Others have used the visibility map (or V-Map) concept. A V-Map is an 'improved' 
Gauss map. As with a G-Map, a V-Map (Wang and Tang 2007) is a spherical region. However, unlike the former, any point on it indicates a direction such that the entire surface remains visible. Balasubramaniam et al. 2003, used the concept of visibility to generate globally collision-free five-axis tool positions. They use a point-cloud representation for the workpiece, a Constructive Solid Geometry (CSG) representation for the tool and an efficient bounding volumes hierarchy. These methods do not tackle the issue of interference between the tool and other parts of the NC-machine, such as clamping devices, or the spindle.

Lauwers et al. 2003, integrated the collision detection into the tool path generation stage. To avoid collision, the tool path generation module, postprocessing and machine simulation have been integrated into one system. The algorithm can avoid collisions between the tool and the part or machine collisions. However, this algorithm cannot be applied for a general form of the tool since a cylindrical approximation was assumed.

Ding et al. 2004, developed a method based on the hierarchical orientated bounding box (OBB) and octree space partition for global interference detection. In this algorithm, the tool and tool-holder are modelled by a hierarchical OBB structure, whereas the workpiece surfaces are approximated by an octree. The interference detection is conducted between the tool OBBs and the grey octants of the surface octree with the separating axis theorem.

A method exists to determine the risk of interference from the cutter when being positioned on the surface to be milled in two stages along a given approach direction (Lee and Chang 1995). The first stage involves a rapid intersection test. If this test is successful, the approach direction considered can be adopted, otherwise a finer test allows it to be ascertained whether it actually cuts the surface; interference is then defined by a set of points. Other methods are based on Configuration space (or C-space) in two dimensions (Morishige et al. 1997, Jun et al. 2003). The Configuration space is defined from the two cutter orientation angles.

From this bibliographical study into collision correction it appears that few methods really take advantage of the possibilities offered by 5-axis machines; very few offer an angular solution domain that will allow the cutter orientation to be optimised or propose satisfactory alternatives. A new corrective method will therefore be devised allowing for rapid and robust resolution, taking both local and global interface into consideration in the processing.

This approach relies on the development of a corrective method for global collisions (Monies et al. 2004).

It has the advantage of proposing a global collision domain to disengage the tool. It allows advantage to be taken of the possibilities offered by 5-axis machines. Moreover, this method uses a set of points to correct the tool with many attendant advantages.

The aim is to take into account local and global collisions by superimposing angular domains (local and global non-interference domains are superimposed to obtain couples of angular parameters such that no interference occurs). Other methods exist but are not suited to the method developed here.

For example, Jensen et al. 2002, presented a method where the tool disengagement seems less effective: one angle is used to correct the collision. Moreover, low collisions seem not to be corrected by this method. In Jun et al. 2003, Collision checking is conducted to part surface facets that are under the projection of the inclined cutter. They use a G-buffer method and construct a C-space to eliminate local and global collision. This method seems to be extremely time consuming. A single corrective module, in angular terms, is applied, contrary to the method proposed here. Another difference concerns the surfaces of the workpieces: the authors use faceted surfaces instead of real surfaces.

However, the method relied on by Monies et al. (2004), did not take local interference (gouging) into account. The present paper explains how to improve it by coupling it with effective management of local interference (§3.3) so as to cater for low collisions (§3.4). An 
overall correction strategy has been developed (\$3.5) and several examples have been studied $(\S 4)$.

\section{INTERFERENCE-FREE TOOL POSITIONING}

\subsection{CorRECTION OF LOCAL COLLISION}

A previously developed positioning method (Rubio et al. 1998, Redonnet et al. 2000) is used to manage local interference between the cutter and the surface. This method allows a cylindrical cutter to be positioned using two corrective angles. Note that this positioning is applicable to a torus milling cutter; to do so all that is required is to provide an interior offset of the value of the cutter toric radius, and an exterior offset of the toric radius for the milled surface to reduce the approach to studying the positioning of a flat ended cutter (Rubio et al. 1998).

A coordinate system local to the surface, noted $\mathfrak{R}_{\mathrm{S}}\left(\mathbf{P}_{\mathbf{C}}, \mathbf{t}, \mathbf{b}, \mathbf{n}\right)$, is defined at the cutter contact point $\mathbf{P}_{\mathbf{C}}$ (cf. figure 2), where $\mathbf{n}$ is the normal to the surface, $\mathbf{t}$ is a tangent to the surface in the machining direction and, $\mathbf{b}=\mathbf{n} \wedge \mathbf{t}$.

Let $\mathfrak{R}_{\mathrm{O}_{1}}\left(\mathbf{P}_{\mathbf{C}}, \mathbf{X}, \mathbf{Y}, \mathbf{Z}\right)$ be a reference local to the cutter. $\mathfrak{R}_{\mathrm{O}_{1}}$ is deduced from the reference $\mathfrak{R}_{\mathrm{S}}$ by the two following geometric transformations:

$\checkmark$ An angle rotation $\beta$ about the axis $\mathbf{t}$, at point $\mathbf{P}_{\mathbf{C}}$;

$\checkmark$ An angle rotation $\alpha$ about the axis $\mathbf{b}$, at point $\mathbf{P}_{\mathbf{C}}$.

Figure 2. Definition of tool positioning in $\mathfrak{R}_{\mathrm{S}}$

The intersection between the cutter and the surface $\mathbf{S}(\mathrm{u}, \mathrm{v})$, both expressed in the reference local to the surface, is sought taking as angular values $\alpha=0$ and $\beta=0$. Resolution of this system provides a discrete number of intersection points, noted $\mathbf{M}_{\mathbf{b i}}$.

Let $\left(\mathrm{x}_{\mathrm{bi}}, \mathrm{y}_{\mathrm{bi}}, \mathrm{z}_{\mathrm{bi}}\right)$ be the co-ordinates of point $\mathbf{M}_{\mathrm{bi}}$ in the local reference of surface $\mathfrak{R}_{\mathrm{s}}$, and $\left(\mathrm{X}_{\mathrm{bi}}, \mathrm{Y}_{\mathrm{bi}}, \mathrm{Z}_{\mathrm{bi}}\right)$ the co-ordinates of point $\mathbf{M}_{\mathrm{bi}}$, in the local reference of the cutter $\mathfrak{R}_{\mathrm{O}_{1}}$. The components $Z_{\mathrm{bi}}$ of points $\mathbf{M}_{\mathbf{b i}}$ in $\Re_{\mathrm{O}_{1}}$ are expressed as follows:

$$
\mathrm{Z}_{\mathrm{bi}}=\left(\mathrm{x}_{\mathrm{bi}} \sin \alpha+\mathrm{z}_{\mathrm{bi}} \cos \alpha\right) \cos \beta-\mathrm{y}_{\mathrm{bi}} \sin \beta
$$

The cutter is in local non-interference if, for each point $\mathbf{M}_{b \mathbf{b}}$, its component $Z_{b i}$ in the reference $\mathfrak{R}_{\mathrm{O}_{1}}$ is less than or equal to 0 .

The equation $\mathrm{Z}_{\mathrm{bi}}=0$ provides a relation between the angular parameters that can be expressed: $\quad \beta=\arctan \left(\left(\mathrm{x}_{\mathrm{bi}} \sin \alpha+\mathrm{z}_{\mathrm{bi}} \cos \alpha\right) / \mathrm{y}_{\mathrm{bi}}\right)$

Figure 3 shows the limit curves for non-interference for eight points of the domain of collision, as well as the solution domain; any couple of angular parameters $(\alpha, \beta)$ located on the bounding curve, shown in thick lines, gives a cutter positioning free of local interference. The couples $(\alpha, \beta)$ inside that bounding curve are also solutions; this is shown on the figure by arrows pointing to the solution domain.

Figure 3. Determination of solution angular parameters 
There is thus an infinity of valid position settings that ensure local non-interference. An additional condition then needs to be imposed to define a unique positioning. The condition chosen tends to limit disengagement between the end of the cutter and the surface. Indeed, there is no purpose to tilting the cutter too much as this would lead to less material being removed and could also lead to problems of vibration (Gilles et al. 2009).

To answer the stated objectives, in what follows the minimal value $\alpha$ of the solution domain will be taken, noted $\alpha_{\text {min }}$ (cf. figure 3) together with the corresponding value $\beta$ (according to Eq. (2)); the cutter will then be only slightly tilted in the direction of milling and clearance between the bottom of the cutter and the surface will be small.

\subsection{CorRECTION OF GLOBAL COLLISIONS}

Let $\left(\alpha_{\text {pos }}, \beta_{\text {pos }}\right)$ be the couple of angles defining positioning of the cutter in the reference $\mathfrak{R}_{\mathrm{S}}$ with $\alpha_{p o s}=\alpha_{\min }$ (§3.1). In this configuration, an interference is detected with a surface $\mathbf{S}_{2}(\mathrm{p}, \mathrm{q})$. The method defined by Monies et al. 2004 to preserve the cutter from global collision uses a set of points. These points are derived from the intersection between the cutter and the surface $\mathbf{S}_{\mathbf{2}}(\mathrm{p}, \mathrm{q})$, as well as the points on the surface inscribed in the intersection domain. The points of the surface domain in interference with the cutter will be noted $\mathbf{M}_{\mathrm{i}}=\mathbf{S}_{\mathbf{2}}\left(\mathrm{p}_{\mathrm{i}}, \mathrm{q}_{\mathrm{i}}\right)$.

Correcting the cutter in relation to a set of points offers many advantages; for example, several surfaces can be processed for collision simultaneously, as well as surfaces that show discontinuities in tangency.

This correction module uses the two positioning angles $\alpha$ and $\beta$.

A new cutter reference is defined noted $\mathfrak{R}_{\mathrm{O}_{2}}\left(\mathbf{O}_{\mathbf{C}}, \mathbf{X}, \mathbf{Y}, \mathbf{Z}\right)$ (cf. figure 4 ). $\mathfrak{R}_{\mathrm{O}_{2}}$ is deduced from the reference $\mathfrak{R}_{\mathrm{O}_{1}}$ by a translation - R.X.

Let $\left(\mathrm{x}_{\mathrm{i}}, \mathrm{y}_{\mathrm{i}}, \mathrm{z}_{\mathrm{i}}\right)$ be the co-ordinates of point $\mathbf{M}_{\mathrm{i}}$ in the local reference of surface $\mathfrak{R}_{\mathrm{S}}$ and $\left(\mathrm{X}_{\mathrm{i}}, \mathrm{Y}_{\mathrm{i}}, \mathrm{Z}_{\mathrm{i}}\right)$ the co-ordinates of point $\mathbf{M}_{\mathrm{i}}$ in the local reference of the cutter $\mathfrak{R}_{\mathrm{O}_{2}}$.

The co-ordinates of points $\mathbf{M}_{\mathbf{i}}$ in $\mathfrak{R}_{\mathrm{O}_{2}}$ are expressed as a function of the co-ordinates defined in $\mathfrak{R}_{\mathrm{S}}$ by the following relations:

$$
\begin{gathered}
\mathrm{X}_{\mathrm{i}}(\alpha)=\mathrm{x}_{\mathrm{i}} \cos \alpha-\mathrm{z}_{\mathrm{i}} \sin \alpha+\mathrm{R} \\
\mathrm{Y}_{\mathrm{i}}(\alpha, \beta)=\mathrm{y}_{\mathrm{i}} \cos \beta+\left(\mathrm{x}_{\mathrm{i}} \sin \alpha+\mathrm{z}_{\mathrm{i}} \cos \alpha\right) \sin \beta
\end{gathered}
$$

A radial distance is defined, noted $\rho_{\mathrm{i}}(\alpha, \beta)$, as a function of the two angular parameters $\alpha$ and $\beta$, characterising the position of a point $\mathbf{M}_{\mathbf{i}}$ in $\Re_{\mathrm{O}_{2}}$ (cf. figure 4):

$$
\rho_{\mathrm{i}}(\alpha, \beta)=\sqrt{\mathrm{X}_{\mathrm{i}}^{2}(\alpha)+\mathrm{Y}_{\mathrm{i}}^{2}(\alpha, \beta)}
$$

Figure 4. Highlighting global interference

The tool initially in interference with the surface is disengaged from the latter if all $\rho_{\mathrm{i}}(\alpha, \beta)>\mathrm{R}$. For a tool disengagement with a value $\Delta \mathrm{R}$ in relation to the surface, a tool radius of $\mathrm{R}+\Delta \mathrm{R}$ is considered. Verification of the condition $\rho_{\mathrm{i}}(\alpha, \beta)=\mathrm{R}+\Delta \mathrm{R}$ for each point $\mathbf{M}_{\mathbf{i}}$ of the global collision domain gives possible positioning settings for the tool.

The two obtainable solutions for equation $\rho_{\mathrm{i}}(\alpha, \beta)=\mathrm{R}+\Delta \mathrm{R}$ are:

$$
\beta_{1 \mathrm{i}}=2 \arctan \left(\left(\mathrm{A}_{1}-\sqrt{\Delta^{\prime}}\right) /\left(\mathrm{A}_{2}+\mathrm{A}_{3}\right)\right) \quad \text { and } \beta_{2 \mathrm{i}}=2 \arctan \left(\left(\mathrm{A}_{1}-\sqrt{\Delta^{\prime}}\right) /\left(\mathrm{A}_{2}-\mathrm{A}_{3}\right)\right)
$$


with $\mathrm{A}_{1}=\mathrm{x}_{\mathrm{i}} \sin \alpha+\mathrm{z}_{\mathrm{i}} \cos \alpha, \quad \mathrm{A}_{2}=\mathrm{y}_{\mathrm{i}}, \mathrm{A}_{3}=\sqrt{(\mathrm{R}+\Delta \mathrm{R})^{2}-\left(\mathrm{x}_{\mathrm{i}} \cos \alpha-\mathrm{z}_{\mathrm{i}} \sin \alpha+\mathrm{R}\right)^{2}}$ and $\Delta^{\prime}=\mathrm{A}_{1}^{2}+\mathrm{A}_{2}^{2}-\mathrm{A}_{3}^{2}$.

The solution values $\beta$ are defined on the domain $\alpha$ as determined by the following double inequality: $\alpha_{\text {inf }} \leq \alpha \leq \alpha_{\text {sup }}, \quad$ with $\alpha_{\text {inf }}=2 \arctan \left(\left(z_{\mathrm{i}}-\sqrt{\mathrm{x}_{\mathrm{i}}^{2}+\mathrm{z}_{\mathrm{i}}^{2}-\Delta \mathrm{R}^{2}}\right) /\left(\Delta \mathrm{R}-\mathrm{x}_{\mathrm{i}}\right)\right) \quad$ and $\alpha_{\text {sup }}=2 \arctan \left(\left(\mathrm{z}_{\mathrm{i}}-\sqrt{\mathrm{x}_{\mathrm{i}}^{2}+\mathrm{z}_{\mathrm{i}}^{2}-4 \mathrm{R}^{2}}\right) /\left(-\mathrm{x}_{\mathrm{i}}+2 \mathrm{R}\right)\right)$.

The two solutions $\beta_{1 \mathrm{i}}(\alpha)$ and $\beta_{2 \mathrm{i}}(\alpha)$ are shown on figure 5 .

Figure 5. Correction curves for a point in the collision domain

For $\alpha$ variant of $\alpha_{\text {inf }}$ to $\alpha_{\text {sup }}$, they represent curves for cutter disengagement for a point $\mathbf{M}_{\mathbf{i}}$ belonging to the lateral collision domain. Any couple $(\alpha, \beta)$ outside these two gives a free cutter position at point $\mathbf{M}_{\mathbf{i}}$.

In order to find the couples of angular parameters ensuring tool disengagement in relation to $\mathbf{S}_{2}(\mathrm{p}, \mathrm{q})$, the bounding curve is constructed, as determined from the intersection of the set of curves for correction for each point $\mathbf{M}_{\mathbf{i}}$; this curve corresponds to the outer envelope of the correction curves.

Then, to find the solution bounding curve, an additional datum needs to be introduced to the previous bounding curves: the material side. The methodology applied is described in detail in Monies et al. 2004; some reminders are defined below.

The equation (4), $\mathrm{Y}_{\mathrm{i}}\left(\alpha_{\text {pos }}, \beta_{\text {pos }}\right)$ is used to calculate all points belonging to the global collision domain and the solutions for $\mathrm{Y}_{\mathrm{i}}(\alpha, \beta)<0$ are noted $\beta_{1 \mathrm{i}}(\alpha), \beta_{2 \mathrm{i}}(\alpha)$ while the solutions for $\mathrm{Y}_{\mathrm{i}}(\alpha, \beta)>0$ are noted $\beta_{3 \mathrm{i}}(\alpha), \beta_{4 \mathrm{i}}(\alpha)$ The functions $\beta_{3 \mathrm{i}}(\alpha)$ and $\beta_{4 \mathrm{i}}(\alpha)$ are equivalent respectively to $\beta_{1 \mathrm{i}}(\alpha)$ and $\beta_{2 \mathrm{i}}(\alpha)$.

The bounding curves $\beta_{1}$ and $\beta_{2}$ are constructed from curves $\beta_{1 \mathrm{i}}$ and $\beta_{2 \mathrm{i}}$ :

- for a given angle $\alpha$, the maximum value of the curves $\beta_{1 \mathrm{i}}(\alpha)$ will belong to the curve $\beta_{1}$.

- for a given angle $\alpha$, the minimum value of the curves $\beta_{2 \mathrm{i}}(\alpha)$ will belong to the curve $\beta_{2}$.

Similarly, bounding curves $\beta_{3}$ and $\beta_{4}$ are constructed from curves $\beta_{3 \mathrm{i}}$ and $\beta_{4 \mathrm{i}}$ :

- for a given angle $\alpha$, the maximum value of the curves $\beta_{3 \mathrm{i}}(\alpha)$ will belong to the curve $\beta_{3}$.

- for a given angle $\alpha$, the minimum value of the curves $\beta_{4 \mathrm{i}}(\alpha)$ will belong to the curve $\beta_{4}$. Construction of the global domain is implemented by superimposing curves $\beta_{1}, \beta_{2}, \beta_{3}$ and $\beta_{4}$, and eliminating the interior zones (cf. figure 6).

Note:

$\alpha_{\text {inf } 12}$ the lower limit $\alpha$ of the bounding curve $\beta_{1}, \beta_{2}$ and $\alpha_{\text {sup 12 }}$ its upper limit $\alpha$. $\alpha_{\text {inf } 34}$ the lower limit $\alpha$ of the bounding curve $\beta_{3}, \beta_{4}$ and $\alpha_{\text {sup } 34}$ its upper limit $\alpha$.

Figure 6. Construction of bounding curves for $\mathrm{Y}_{\mathrm{i}}(\alpha, \beta)<0$

A point $\mathbf{M}_{\mathrm{i}}$, with co-ordinates $\left(\mathrm{X}_{\mathrm{i}}, \mathrm{Y}_{\mathrm{i}}, \mathrm{Z}_{\mathrm{i}}\right)$, is defined in one of the four zones of the tool in relation to the criteria below: 
Zone 1: $\quad 0 \leq \mathrm{X}_{\mathrm{i}} \leq \mathrm{R},-\mathrm{R} \leq \mathrm{Y}_{\mathrm{i}} \leq 0, \quad$ Zone $2: \quad-\mathrm{R} \leq \mathrm{X}_{\mathrm{i}} \leq 0,-\mathrm{R} \leq \mathrm{Y}_{\mathrm{i}} \leq 0$

Zone 3: $\quad 0 \leq \mathrm{X}_{\mathrm{i}} \leq \mathrm{R}, 0 \leq \mathrm{Y}_{\mathrm{i}} \leq \mathrm{R}, \quad$ Zone $4: \quad-\mathrm{R} \leq \mathrm{X}_{\mathrm{i}} \leq 0,0 \leq \mathrm{Y}_{\mathrm{i}} \leq \mathrm{R}$

Zones 1 and 3 define the front of the tool and zones 2 and 4 define the rear of the tool. Note $\mathrm{n}_{\mathrm{X}}, \mathrm{n}_{\mathrm{Y}}, \mathrm{n}_{\mathrm{Z}}$ the components of the normal to the surface of a point $\mathbf{M}_{\mathrm{i}}$ in the co-ordinate system $\mathfrak{R}_{\mathrm{O}_{2}}$.

Three definitions relating to frontal, rear and lateral collision are presented:

Frontal collision occurs in the three following cases:

- when all $X_{\mathrm{i}}$ are positive

- the collision occurs in the two zones of the tool whose zones are \{Zone 1, Zone 3\}

- the collision occurs in the 4 zones of the tool and at least one of the points $\mathbf{M}_{\mathbf{i}}$ has a component $\mathrm{n}_{\mathrm{x}}<0$.

Rear collision occurs in the three following cases:

- when all $X_{\mathrm{i}}$ are negative

- the collision occurs in two zones of the tool whose zones are \{Zone 2, Zone 4$\}$

- the collision occurs in 4 zones of the tool and at least one of the points $\mathbf{M}_{\mathbf{i}}$ has a component $\mathrm{n}_{\mathrm{x}}>0$.

Lateral collision occurs in all other cases

For a frontal collision: $\alpha_{\text {sup }}=\alpha_{\text {pos }}$; for a rear collision: $\alpha_{\text {inf }}=\alpha_{p o s}$.

An example of disengagement curves for a tool in frontal collision is given in figure 7. Cutter with radius $\mathrm{R}=20 \mathrm{~mm}$, gap $\Delta \mathrm{R}=0.5 \mathrm{~mm}$ and positioning angles:

$\alpha_{p o s}=3^{\circ}, \quad \beta_{p o s}=0^{\circ}$

Figure 7. Curves for cutter disengagement $\beta_{2}, \beta_{4}$

\subsection{LOCAL AND GLOBAL INTERFERENCE-FREE POSITIONING}

It can be seen that in all events, there are an infinite number of tool position settings allowing interference with the surface to be corrected, initially in collision. An additional constraint now needs to be defined, ensuring there is a unique solution.

The limit curves for end positioning as defined previously ( $\$ 3.1)$ will be used in association with the tool correction curves (\$3.2) to determine whether it is possible to obtain a couple of angular values $(\alpha, \beta)$ that ensure both local non-interference and global non-collision. If these two conditions cannot be fulfilled, priority will always go to tool correction cancelling out global collision; the method to cancel out local interference will then be defined.

Let $\beta_{1}, \beta_{2}, \beta_{3}, \beta_{4}$ be the limit curves defining the domain of lateral disengagement of the tool (\$3.2). Note $\beta_{\mathrm{b} 1}$ and $\beta_{\mathrm{b} 2}$ the limit curves delimiting the domain of local non-interference at the end of the tool $(\$ 3.1)$. Now seek the intersections between the bounding curves $\beta_{\mathrm{j}}$, $\mathrm{j} \in\{1,2,3,4\}$, and curves $\beta_{\mathrm{b} 1}$ and $\beta_{\mathrm{b} 2}$.

Note that in the case where $\alpha_{\text {pos }}=\alpha_{\text {min }}$, the local and global non-interference cannot be reached without having to lift the tool, only in the case of a rear collision or a lateral collision.

Figure 8a. $j \in\{2,4\}$

Figure 8b. $\mathrm{j} \in\{1,3\}$ 
Figure 8c. $j \in\{2,4\}$

Figure $8 \mathrm{~d} . \quad \mathrm{j} \in\{1,3\}$

\section{Figure 8. Superimposition of the collision domains}

In all the cases shown in figures $8 \mathrm{a}, 8 \mathrm{~b}, 8 \mathrm{c}$ and $8 \mathrm{~d}$, the two couples of angular parameters $\left(\alpha_{1 \cap}, \beta_{1 \cap}\right)$ and $\left(\alpha_{2 \cap}, \beta_{2 \Omega}\right)$ offer a tool positioning free both from local and global interference. In all instances the couple $\left(\alpha_{1 \cap}, \beta_{1 \cap}\right)$ whose angle value $\alpha$ is closest to $\alpha_{\text {pos }}$ will be chosen. If no global correction curve intersects the two limit curves defining the domain of local noninterference, then the method described below will be applied.

For each of the solution global correction curves, the components $Z_{b i}$ of points $\mathbf{M}_{\mathbf{b i}}$ expressed in $\Re_{\mathrm{O}_{1}}$ will be calculated for each angle $\alpha$ defined between its limit bounds, taking for angular value $\beta$ the value defined by $\beta_{\mathrm{j}}(\alpha)$. For each $\alpha$ the maximal component $\mathrm{Z}_{\mathrm{bi}}$ will be determined. Once the angular domain $\alpha$ has been scanned, the angle $\alpha$ associated with the minimum of the maximal values for gaps between the end of the tool and the surface will be chosen. If the number of points $\mathbf{M}_{\mathbf{b i}}$ of the interference domain at the end of the tool is noted $N_{\text {b }}$, the method can be expressed in the following algorithmic form:

$$
\begin{aligned}
& \text { For } \alpha_{\text {inf }} \leq \alpha \leq \alpha_{\text {sup }} \\
& \qquad \begin{array}{r}
\text { For } 1 \leq \mathrm{i} \leq N_{\mathrm{b}} \\
\left\{\quad \mathrm{Z}_{\mathrm{bi}}=\mathrm{x}_{\mathrm{bi}} \cos \left(\beta_{\mathrm{j}}(\alpha)\right) \sin \alpha-\mathrm{y}_{\mathrm{bi}} \sin \left(\beta_{\mathrm{j}}(\alpha)\right)+\mathrm{z}_{\mathrm{bi}} \cos \alpha \cos \left(\beta_{\mathrm{j}}(\alpha)\right)\right. \\
\left.\mathrm{Z}_{\max }=\operatorname{MAX}\left\{\mathrm{Z}_{\mathrm{bi}}\right\} \quad\right\}
\end{array} \\
& \alpha_{\text {solution }} \text { such that: } \operatorname{MIN}\left\{\mathrm{Z}_{\max }\right\}
\end{aligned}
$$

From the angular value $\alpha_{\text {solution }}$, the corresponding value of angle $\beta$ located on the solution bounding curve for global correction is obtained directly.

For lateral collisions, either the above procedure can be applied, or angle $\alpha_{\text {pos }}$ can be taken for the correction angle $\alpha$ to deduce the angle $\beta$ for correction.

Note $\left(\alpha_{c o r}, \beta_{c o r}\right)$ the couple of angular parameters chosen, giving a corrected positioning for the tool, freed from any global collision.

In this instance, where the solution bounding curve for global correction does not intersect the two limit curves defining the local non-interference domain, the method allowing for disengagement of the tool and defining the axis of the cutter using the couple of angles $\left(\alpha_{c o r}, \beta_{c o r}\right)$ was proposed. But the tool is for the time being in local interference with the surface $\mathbf{S}(\mathrm{u}, \mathrm{v})$, since the couple $\left(\alpha_{\text {cor }}, \beta_{\text {cor }}\right)$ is not located on one of the two limit curves of the local non-interference domain, or inside the domain; the value for maximum interference is given by $\operatorname{MIN}\left\{\mathrm{Z}_{\text {max }}\right\}$ defined in the algorithm that will subsequently be noted: $\mathrm{Z}_{\mathrm{MAX}}$. The cutter will therefore be raised, along its axis, in the reference $\mathfrak{R}_{\mathrm{O}_{1}}$, by value $\mathrm{Z}_{\mathrm{MAX}}$, to cancel interference between the bottom of the cutter and the surface $\mathbf{S}(\mathrm{u}, \mathrm{v})$. The tool will then be positioned to be free from both global and local interference effects.

\subsection{MANAGING LOW COLLISIONS}

This correction module has limitations when global collision is extremely low, close to the end of the tool. In this case, angle $\beta$ must swivel extremely significantly to disengage the 
cutter from the surface. In some cases, the correction angle may even be too great, leading to problems in cutting and limitations in movement by the machine stops. Angle $\beta$ will be limited by a technological value that will in what follows be noted $\beta_{\text {limite }}$. In limit cases, the following will thus obtain: $\beta_{\text {cor }}=\beta_{\text {limite }}$.

An additional correction method will now be implemented that will cater for low global collisions of the tool.

If initially the cutter is positioned by the couple of angles $\left(\alpha_{\text {pos }}, \beta_{\text {pos }}\right)$ and in global collision, and the correction module $(\alpha, \beta)$ fails to disengage it completely, the correction module $(\alpha, \gamma)$ can be applied. This is defined below.

This correction module positions the cutter by swivelling it by an angle $\gamma$ about the axis $\mathbf{n}$, at point $\mathbf{P}_{\mathbf{C}}$, and with an angle $\alpha$ about axis $\mathbf{b}$, at point $\mathbf{P}_{\mathbf{C}}$ (figure 9 ).

As for module $(\alpha, \beta)$, the points of the global collision domains $\mathbf{M}_{\mathbf{i}}$ will be used to disengage the tool.

Two eventualities need to be distinguished:

$>$ Either the correction module $(\alpha, \gamma)$ is applied directly from the collision domain defined by the cutter position $\left(\alpha_{p o s}, \beta_{p o s}\right)$. In this instance, for subsequent reasoning, it will be considered that $\beta_{\text {cor }}=\beta_{\text {pos }}$.

$>$ Or module $(\alpha, \gamma)$ is applied from the global collision domain defined by the cutter position $\left(\alpha_{c o r}, \beta_{c o r}\right)$, considering $\beta_{\text {cor }}=\beta_{\text {limite }}$.

Let $\Re_{\mathrm{O}_{3}}\left(\mathbf{P}_{\mathbf{C}}, \mathbf{X}, \mathbf{Y}, \mathbf{Z}\right)$ and $\Re_{\mathrm{O}_{4}}\left(\mathbf{O}_{\mathbf{C}}, \mathbf{X}, \mathbf{Y}, \mathbf{Z}\right)$ be two local references related to the tool.

$\mathfrak{R}_{\mathrm{O}_{3}}$ is deduced from reference $\mathfrak{R}_{\mathrm{S}}$ by the three following geometric transformations:

$\checkmark$ A rotation of angle $\gamma$ about the axis $\mathbf{n}$, at point $\mathbf{P}_{\mathbf{C}}$;

$\checkmark$ A rotation of angle $\beta_{\text {cor }}$ about the axis $\mathbf{t}$, at point $\mathbf{P}_{\mathbf{C}}$;

$\checkmark$ A rotation of angle $\alpha$ about the axis $\mathbf{b}$, at point $\mathbf{P}_{\mathbf{C}}$;

$\mathfrak{R}_{\mathrm{O}_{4}}$ is deduced from $\mathfrak{R}_{\mathrm{O}_{3}}$ by a translation - R.X (figure 9 ).

Figure 9. Local reference $\mathfrak{R}_{\mathrm{O}_{4}}$

Let $\left(\mathrm{x}_{\mathrm{i}}, \mathrm{y}_{\mathrm{i}}, \mathrm{z}_{\mathrm{i}}\right)$ be the co-ordinates of point $\mathbf{M}_{\mathrm{i}}$ in the local reference of surface $\mathfrak{R}_{\mathrm{S}}$, and $\left(\mathrm{X}_{\mathrm{i}}, \mathrm{Y}_{\mathrm{i}}, \mathrm{Z}_{\mathrm{i}}\right)$ the co-ordinates of point $\mathbf{M}_{\mathrm{i}}$ in the local reference of the cutter $\mathfrak{R}_{\mathrm{O}_{4}}$. The co-ordinates of points $\mathbf{M}_{\mathbf{i}}$ in $\mathfrak{R}_{\mathrm{O}_{4}}$ are expressed as follows:

$\mathrm{X}_{\mathrm{i}}=\left(\mathrm{x}_{\mathrm{i}} \cos \alpha-\mathrm{z}_{\mathrm{i}} \sin \alpha\right) \cos \gamma+\left(\mathrm{x}_{\mathrm{i}} \sin \beta_{c o r} \sin \alpha+\mathrm{y}_{\mathrm{i}} \cos \beta_{c o r}+\mathrm{z}_{\mathrm{i}} \sin \beta_{c o r} \cos \alpha\right) \sin \gamma+\mathrm{R}$

$\mathrm{Y}_{\mathrm{i}}=\left(\mathrm{x}_{\mathrm{i}} \sin \beta_{c o r} \sin \alpha+\mathrm{y}_{\mathrm{i}} \cos \beta_{c o r}+\mathrm{z}_{\mathrm{i}} \sin \beta_{c o r} \cos \alpha\right) \cos \gamma-\left(\mathrm{x}_{\mathrm{i}} \cos \alpha-\mathrm{z}_{\mathrm{i}} \sin \alpha\right) \sin \gamma$

$\mathrm{Z}_{\mathrm{i}}=\mathrm{x}_{\mathrm{i}} \cos \beta_{c o r} \sin \alpha-\mathrm{y}_{\mathrm{i}} \sin \beta_{c o r}+\mathrm{z}_{\mathrm{i}} \cos \beta_{c o r} \cos \alpha$

A radial distance is defined $\rho_{\mathrm{i}}=\sqrt{\mathrm{X}_{\mathrm{i}}^{2}+\mathrm{Y}_{\mathrm{i}}^{2}}$ as a function of the two angular parameters positioning the tool, that is $\alpha$ and $\gamma$. Disengagement of the tool is obtained by applying the relation: $\rho_{\mathrm{i}}=\mathrm{R}+\Delta \mathrm{R}$. This relation developed is equal to:

$$
\mathrm{B}_{1} \sin \gamma+\mathrm{B}_{2} \cos \gamma=\left(2 \mathrm{R} \cdot \Delta \mathrm{R}+\Delta \mathrm{R}^{2}-\left(\mathrm{B}_{1}^{2}+\mathrm{B}_{2}^{2}\right)\right) / 2 \mathrm{R}
$$


with: $\mathrm{B}_{1}=\mathrm{x}_{\mathrm{i}} \sin \beta_{c o r} \sin \alpha+\mathrm{y}_{\mathrm{i}} \cos \beta_{c o r}+\mathrm{z}_{\mathrm{i}} \sin \beta_{c o r} \cos \alpha$ and $\mathrm{B}_{2}=\mathrm{x}_{\mathrm{i}} \cos \alpha-\mathrm{z}_{\mathrm{i}} \sin \alpha$

Resolution of the equation $\rho_{\mathrm{i}}=\mathrm{R}+\Delta \mathrm{R}$ gives the two following solutions:

and

$$
\begin{aligned}
& \gamma_{1 \mathrm{i}}=2 \arctan \left(\frac{\mathrm{B}_{1}+\sqrt{\mathrm{B}_{1}^{2}+\mathrm{B}_{2}^{2}-\left(\left[2 \mathrm{R} \cdot \Delta \mathrm{R}+\Delta \mathrm{R}^{2}-\left(\mathrm{B}_{1}^{2}+\mathrm{B}_{2}^{2}\right)\right]^{2} / 4 \mathrm{R}^{2}\right)}}{\mathrm{B}_{2}+\left(2 \mathrm{R} \cdot \Delta \mathrm{R}+\Delta \mathrm{R}^{2}-\left(\mathrm{B}_{1}^{2}+\mathrm{B}_{2}^{2}\right)\right) / 2 \mathrm{R}}\right) \\
& \gamma_{2 \mathrm{i}}=2 \arctan \left(\frac{\mathrm{B}_{1}-\sqrt{\mathrm{B}_{1}^{2}+\mathrm{B}_{2}^{2}-\left(\left[2 \mathrm{R} \cdot \Delta \mathrm{R}+\Delta \mathrm{R}^{2}-\left(\mathrm{B}_{1}^{2}+\mathrm{B}_{2}^{2}\right)\right]^{2} / 4 \mathrm{R}^{2}\right)}}{\mathrm{B}_{2}+\left(2 \mathrm{R} \cdot \Delta \mathrm{R}+\Delta \mathrm{R}^{2}-\left(\mathrm{B}_{1}^{2}+\mathrm{B}_{2}^{2}\right)\right) / 2 \mathrm{R}}\right)
\end{aligned}
$$

The curves for correction of the cutter for a point of the global collision domain are shown in figures $10 \mathrm{a}$ and $10 \mathrm{~b}$.

Figure 10a: Standard curves $\left(\mathrm{Y}_{\mathrm{i}}<0\right)$

Figure 10b: Standard curves $\left(Y_{i}>0\right)$

Figure 10. Standard curves

Use of this corrective module is limited to lateral collisions and rear collisions. The case of frontal collision \{Zone 1, Zone 3 \} close to the cutter is unlikely. There will necessarily be a high frontal collision jointly; once this high collision has been corrected by application of the module $(\alpha, \beta)$, the tool will then be disengaged in relation to the low interference zone. The case of a low rear collision, although plausible, should nevertheless be exceptional. Within the scope of regular use of this correction module, all the $Y_{i}$ components of points of collision will thus be of the same sign. Information on the material side is therefore available with the result that, in the general case, the tool will be positioned using a single solution $\gamma(\alpha)$ :

If all $Y_{\mathrm{i}}<0$, the disengagement solution is given by: $\gamma_{1 \mathrm{i}}$

If all $Y_{\mathrm{i}}>0$, the disengagement solution is given by: $\gamma_{2 \mathrm{i}}$

Figures 11a. 11b illustrate the case of a collision where all $Y_{\mathrm{i}}$ are negative. In order to present only a very limited number of points of collision, the domain of collision in this example is assimilated into a thin interference zone.

Figure 11a: Bounding curve for tool disengagement Figure 11b: Lateral collision

Figure 11. Correction of a low collision

Knowing the material size from the information given by the sign of the $Y_{i}$ values, the correction value $\gamma$ is thus equal to $\gamma_{1 \mathrm{i}}$. Figure 10a shows disengagement curves $\gamma_{l i}\left(\alpha, x_{i}, y_{i}, z_{i}\right)$ for each of the five points of the collision domain. The bounding curve for correction of the tool $\gamma_{1}$ is shown in thick lines and an arrow shows the cutter disengagement domain.

The bounding curve for correction of the tool shown in the example is determined as follows: for a given angle $\alpha$ locally, it is defined by the minimum value $\gamma_{1 \mathrm{i}}\left(\alpha, \mathrm{x}_{\mathrm{i}}, \mathrm{y}_{\mathrm{i}}, \mathrm{z}_{\mathrm{i}}\right)$.

Remark: For the case where all $\mathrm{Y}_{\mathrm{i}}$ values are positive, the bounding curve for correction of the cutter is constructed as follows: for a given angle $\alpha$, locally, it is defined by the maximum value $\gamma_{2 \mathrm{i}}\left(\alpha, \mathrm{x}_{\mathrm{i}}, \mathrm{y}_{\mathrm{i}}, \mathrm{z}_{\mathrm{i}}\right)$. 
Where the two modules are combined, angles $\alpha_{c o r}, \beta_{c o r}$ and the corresponding angle $\gamma$ that will be noted $\gamma_{\text {cor }}$ can be taken.

Where the module is used alone, $\beta=\beta_{\text {pos }}$ can be taken and for $\alpha$ the same angle value as that for previous positioning. The aim is to achieve continuity in the tool's tilt for improved cutting. The value of the correction angle $\gamma$ can then be deduced.

In general, the cutter will be in local interference. In this case, the intersection between the surface and the end of the cutter (\$3.3) will be sought and a discrete number of points will be defined, from which the tool will be disengaged, translating it along its axis, by the value of the maximum component $\mathrm{Z}_{\mathrm{bi}}$.

When global collisions are detected, the corrective module $(\alpha, \beta)$ is applied. This module can fail, however, in not completely disengaging the cutter. In this case, use of the corrective module $(\alpha, \gamma)$ can be resorted to; the tool can be corrected from its position as defined by the couple of parameters $\left(\alpha_{p o s}, \beta_{p o s}\right)$ or from the couple $\left(\alpha_{c o r}, \beta_{c o r}\right)$ with $\beta_{c o r}=\beta_{\text {limite }}$.

\subsection{OVERALL CORRECTION STRATEGY}

This procedure can be improved by considering that each corrective module has a quite specific use and will only be really effective in a given context: module $(\alpha, \beta)$ is good in managing collisions located as from a certain height, whereas module $(\alpha, \gamma)$ manages collisions close to the end of the cutter efficiently.

A height can be defined to delimit how the two modules are used with module $(\alpha, \beta)$ to correct 'high' collisions and module $(\alpha, \gamma)$ covering 'low' collisions.

The domain for use of the current angle $\alpha$ is defined (Monies et al. 2004) for $\mathrm{R} \leq \sqrt{\mathrm{x}_{\mathrm{i}}^{2}+\mathrm{z}_{\mathrm{i}}^{2}} / 2$, considering $\Delta \mathrm{R}=0$, that is $\mathrm{z}_{\mathrm{i}} \geq \sqrt{(2 \mathrm{R})^{2}-\mathrm{x}_{\mathrm{i}}^{2}}$. In addition, for low angles $\alpha, \beta$, the component $\mathrm{z}_{\mathrm{i}}$ of a point $\mathbf{M}_{\mathrm{i}}$ in $\Re_{\mathrm{S}}$ is scarcely different from its component $\mathrm{Z}_{\mathrm{i}}$ expressed in $\mathfrak{R}_{\mathrm{O}_{2}}$. A separation limit for domains of collision for $\mathrm{Z}_{\mathrm{i}}=1.5 \mathrm{R}$ is thus chosen. The cutter diameter could have been chosen for this height, with such a choice not in any way impairing the general validity of the corrective method. Two definitions are thus introduced to determine under what conditions the collision is considered to be 'high' or 'low'.

The collision will be considered to be 'low' if:

more than $80 \%$ of points of the global collision domain bounding have a component $\mathrm{Z}_{\mathrm{i}}$, expressed in the tool reference of less than 1.5 times the cutter radius.

Where this is not the case, the collision will be considered to be 'high'.

Where the collision domain satisfies neither of the two definitions (cf. figure 12), it will be split into two with one 'high' $D_{l h}$ and the other 'low $D_{l b}$ and the separation limit being defined by $\mathrm{Z}_{\mathrm{i}}=1.5 \mathrm{R}$.

Figure 12. Partition of the collision domain

The correction strategy can be defined as follows: 


\section{EXAMPLES}

\subsection{EXAMPLE OF APPLICATION ON A MACHINING PASS}

Figure 14 shows application of the corrective method developed on a machining pass corrected from any local and global collision. Fifteen position settings are defined : 7 without global collision, 2 frontal collisions, 1 rear collision and 5 lateral collisions.

The points of contact between the cutter and the milled surface are defined on the curve resulting from the intersection between a guide plane (cf. figure 14) and the milled surface. Orientation of the plane is defined in terms of the workpiece machining strategy. The cutter used is a cylindrical milling cutter with a $40 \mathrm{~mm}$ diameter, with cutting in the centre and the gap between the tool and the lateral surface is defined by $\Delta \mathrm{R}=1 \mathrm{~mm}$.

Figure 14. Corrected tool path 


\subsubsection{DetaILED EXAMPLE OF MANAGING A LATERAL COLLISION}

This positioning corresponds to a 9th of the pass (cf. figure 14).

According to the domain of local non-interference at the end of the tool (cf. figure 17), the couple of angular parameters corresponding to the intersection of the bounding curves $\beta_{\mathrm{b} 1}$ and $\beta_{\mathrm{b} 2}$ is given by: $\alpha_{p o s}=6.45^{\circ}, \beta_{p o s}=-0.15^{\circ}$.

With this orientation, the cutter is in global collision with the side wall of the workpiece (cf. figure 15). The global collision domain includes 26 bounding points (cf. figure 16) and 68 points in all, considering the points of the surface inside the intersection.

Superimposition of the local and global collision domains gives a couple of angular values, cancelling out any interference on the cutter (cf. figure 17).

Figure 15. Lateral collision

Figure 16. Bounding points of the global collision domain

Figure 17. Superimposition of the collision domains

The intersection occurs between curve $\beta_{2}$ and curve $\beta_{\mathrm{b} 2}$ (cf. figure 17); the corresponding angular parameters are $\alpha=17.26^{\circ}, \beta=-1.96^{\circ}$. The tool is thus free of local and global collision so it can be oriented by adopting the following parameters: $\alpha_{\text {cor }}=17.26^{\circ}, \quad \beta_{\text {cor }}=-1.96^{\circ}$.

If there is a preference to orient the cutter with a smaller angle $\alpha, \alpha_{c o r}=\alpha_{p o s}$ can be taken.

After correction of interference, the angular positioning parameters are then:

$$
\alpha_{\text {cor }}=6.45^{\circ}, \quad \beta_{c o r}=-6.04^{\circ}
$$

In this last case, the cutter is then translated axially by the distance $\mathrm{Z}=1.35 \mathrm{~mm}$ to cancel local interference (cf. figure 18).

Figure 18. Local and lateral correction of the cutter

\subsubsection{Processing the SET OF COLlisions for the MACHINING PASS}

Table 1 illustrates the 15 cutter position settings free from local and global collision.

Table 1. Description of position settings

For cutter position settings $6,7,8,9,10$ that correct lateral collision from the start, $\alpha_{c o r}=\alpha_{p o s}$ is taken, leading the cutter to be raised slightly to cancel out local interference. With respect to positioning \# 11 that corrects a rear collision, the intersection of the global collision angular domain with that for local collision gives the solution angular couple to best orient the cutter. The disengagement curve $\beta_{2}$ intersects the two bounding curves of the domain at the end of the tool, $\beta_{\mathrm{b} 1}$ and $\beta_{\mathrm{b} 2}$, respectively at $\alpha=8.96^{\circ}$ and $\alpha=12.16^{\circ}$. The value retained corresponds to the closest $\alpha_{\text {pos }}$ (\$3.3); whence: $\alpha_{c o r}=8.96^{\circ}$ and $\beta_{\text {cor }}=-0.013^{\circ}$.

It can be seen that the cutter has continuous movement, without excentration of one positioning in relation to others. The method proposed effectively positions the cutter and provides it with perfect control in relation to the surface tested in global collision. 


\subsection{COMPARISON WITH A CAM SOFTWARE}

The present article's tool positioning was compared with that proposed by CAM software used in aeronautics. A case similar to that presented in figure 13 has been studied.

The CAM software uses two positioning angles $\alpha$ and $\beta$. It allows two possibilities: $\alpha$ can vary in an angular domain but $\beta$ takes a single value, or conversely, $\alpha$ is fixed and $\beta$ can vary. The two angles cannot vary simultaneously, meaning there are less solutions to position the tool. Moreover, the tool cannot be rotated along the normal surface: angle $\gamma$ does not exist and the software is unable to correct low collisions.

In this example, cf. figure 20 , the software gives a positioning without collision the angular positioning parameters are $\alpha=0, \beta=65.9^{\circ}$ ), but in practice, this positioning is not suitable: the tool has too much tilt and this will lead to vibrations.

Moreover, there are considerable risks of collisions with the tool-holder. It can also be seen that the tool cannot remove more material to the right. If the CAM software operator programs another tool pass, the tool will be in low collision, and there will be no possibility of using an angle $\gamma$. It will not be possible to prevent tool collision.

$$
\begin{aligned}
& \text { Figure 20. CAM software: } \alpha=0, \beta \in\left[-70^{\circ}, 70^{\circ}\right] \\
& \text { angular positioning parameters : }\left(\alpha=0, \beta=65,9^{\circ}\right)
\end{aligned}
$$

The proposed positioning gives a better orientation (cf. figure 21). The tool is not so heavily tilted $\left(\alpha=0.78^{\circ}, \beta=4,63^{\circ}, \gamma=-6.2^{\circ}\right)$ and can remove more material without having to be changed to a smaller size/replaced b a smaller cutter. Moreover it can manage complex situations as with low collisions.

Figure 21. Corrected positioning $\left(\alpha=0.78^{\circ}, \beta=4,63^{\circ}, \gamma=-6.2^{\circ}\right)$

\section{Conclusion}

To end mill workpieces with free-form shapes, positioning was adopted using two corrective angles and a set of points to cancel out local interference; these points resulting from the intersection of the end of the tool with the machined surface. Work was then conducted to seek a means to eliminate interference with the body of the cutter. A corrective module was 
presented. This was based on two cutter positioning angles and on a set of points belonging to the global collision domain so as to disengage the tool; the two local and global noninterference domains were then superimposed to obtain a couple of angular parameters such that no interference occurs. A correction procedure was also defined for the case where the cutter disengagement curves do not intersect. An approach for the management of low collisions was also defined. This approach, combined with management of high collisions provides an opportunity to manage cutter disengagements effectively and use low positioning angles in the tool local reference. This method is capable of managing local and global collisions, even in complex cases, where the tool is surrounded by a large number of obstacles. To manage global collisions, a strategy was defined to manage "high" collisions and "low" collisions. Few existing methods can correct tools in low collision. Moreover, with this strategy, it can be ensured that the tool will not be too inclined (excess tilt) once corrected. The tool path computed by this method allows drastic changes in the tool's orientation between neighbouring tool contact points to be avoided. Using the two modules, extreme changes in orientation that are not feasible in real machining due to the physical limit on angular velocity and acceleration of the rotary motion of the machine tool can be dispensed with. Another advantage in the proposed method lies in the fact that it is not restricted to the shape of the tool. The tool-holder, for example, can be taken into account when positioning the cutter.

This procedure was defined for a flat ended tool but it can also be used for a toric end cutter. Finally, extremely rapid tool positioning exempt from local and global interferences was obtained.

\section{References}

Balasubramaniam, M., Sarma, S.E., Marciniak, K., 2003. Collision-free finishing toolpaths from visibility data, Computer-Aided Design, 35 (4), 359-374.

Bergen, G., 1997. Efficient collision detection of complex deformable models using AABB trees, Journal of Graphics Tools, 2, 1-13.

Chen, T., Zhong, Y., Zhou, J., 2002. Determination of cutter orientation for five-axis sculptured surface machining with a filleted-end, International Journal of Advanced Manufacturing Technology, 20, 735-740.

Ding, S., Mannan, M.A., Poo, A.N., 2004. Oriented bounding box and octree based global interference detection in 5-axis machining of free-form surfaces, Computer-Aided Design, 36 (13), 1281-1294.

Elber, G., Zussman, E., 1998. Cone visibility decomposition of freeform surfaces, Computer Aided Design, 30, 315-320.

Gilles, P., Cohen, G., Monies, F., Rubio, W., 2009. Dynamic behaviour improvement for a torus milling cutter using balance of the transversal cutting force, International Journal of Advanced Manufacturing Technology, 40, 669-675.

Gray, P.J., Bedi, S., and Ismail, F., 2005. Arc-intersect method for 5-axis tool positioning, Computer-Aided Design, 37 (7), 663-674.

Jensen, C.G., Red, W.E., Pi, J., 2002. Tool selection for five-axis curvature matched machining, Computer-Aided Design, 34, 251-266.

Jun, C.S., Cha, K., Lee, Y.S., 2003. Optimizing tool orientation for 5-axis machining by configuration-space search method, Computer-Aided Design, 35, 549-566.

Lauwers, B., Dejonghe, P., Kruth, J.P., 2003. Optimal and collision free tool posture in fiveaxis machining through the tight integration of tool path generation and machine simulation, Computer-Aided Design, 35 (5), 421-432. 
Lee, Y.S., Chang, T.C., 1995. 2-Phase approach to global tool interference avoidance in 5axis machining, Computer Aided Design, 27, 715-729.

Lee, Y.S., Ji, H., 1997. Surface interogation and machining strip evaluation for 5-axis CNC die and mold machining, International Journal of Production Research, 35, (1), 225-252.

Monies, F., Mousseigne, M., Redonnet, J.M., Rubio, W., 2004. Determining a collision-free domain for the tool in five-axis machining, International Journal of Production Research, 42, $\mathrm{n}^{\circ} 21,4513-4530$.

Morishige, K., Kase, K., Takeuchi, Y., 1997. Collision-free tool path generation using dimensional C-space for 5-axis control machining, International Journal of Advanced Manufacturing Technology, 13, 393-400.

Klosowski, J.T., 1998. Efficient collision detection for interactive 3D graphics and Virtual environments, Thesis, State University of New York at Stony Brook.

Rao, A., Sarma, R., 2000. On local gouging in five-axis sculptured surface machining using flat-end tools, Computer-Aided Design, 32 (7), 409-420.

Redonnet, J.M., Rubio, W., Monies F., Dessin, G., 2000. Optimising tool positioning for endmill machining of free-form surfaces on 5-axis machines for both semi-finishing and finishing. International, Journal of Advanced Manufacturing Technology, 16, 383-391.

Rubio, W., Lagarrigue, P., Dessein, G., Pastor, F., 1998. Calculation of tool paths for a torus mill on free-form surfaces on 5-axis machines with detection and elimination of interference. International Journal of Advanced Manufacturing Technology, 14, 13-20.

Takeuchi, Y., Morishige, K., Yokoyama, M., Hisaki, T., 1995. 5-Axis control machining using side-milling cutter, Journal of Advanced Automation Technology, 7, 60-65.

Tang, T.D., Bohez, E., Koomsap, P., 2007. The sweep plane algorithm for global collision detection with workpiece geometry update for five-axis NC machining, Computer-Aided Design, 39 (11), 1012-1024.

Wang, X.C., Ghosh, S.K., Li, Y.B., Wu, X.T., 1993. Curvature catering - a new approach in manufacture of sculptured surfaces, Journal of Materials Processing Technology, 38, 159-194. Wang, N., Tang, K., 2007. Automatic generation of gouge-free and angular-velocitycompliant five-axis toolpath, Computer-Aided Design, 39 (10), 841-852.

Wang, N., Tang, K., 2008. Five-axis tool path generation for a flat-end tool based on isoconic partitioning, Computer-Aided Design, 40, 1067-1079. 


\section{FIGURE}

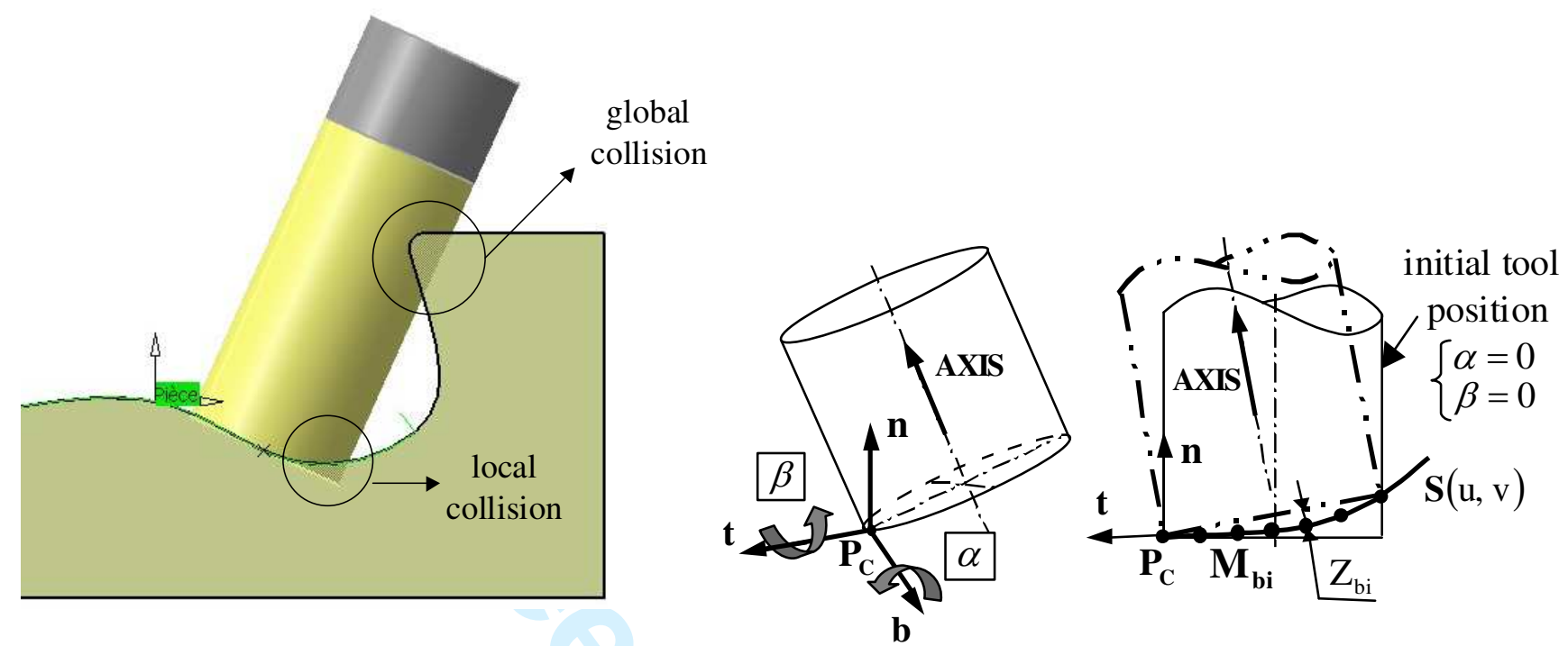

Figure 1. Local and global collisions

Figure 2. Definition of tool positioning in $\mathfrak{R}_{\mathrm{S}}$

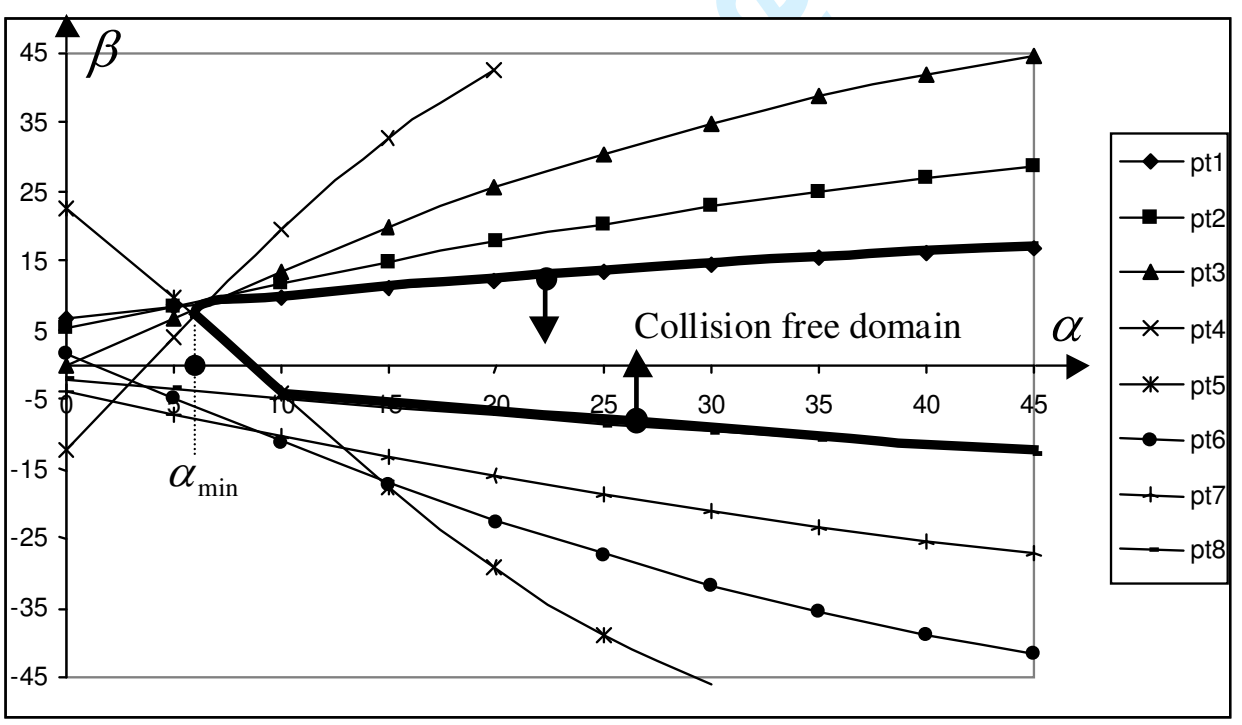

Figure 3. Determination of solution angular parameters 


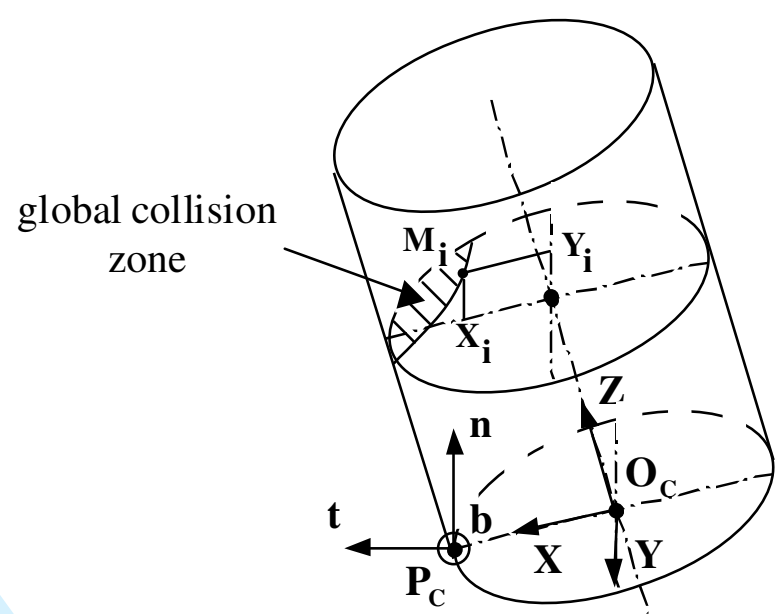

Figure 4. Highlighting global interference

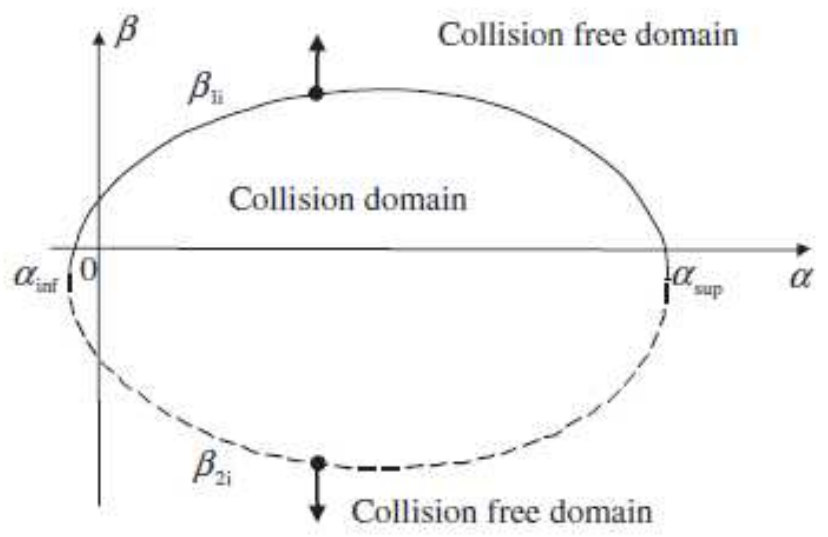

Figure 5. Correction curves for a point in the collision domain

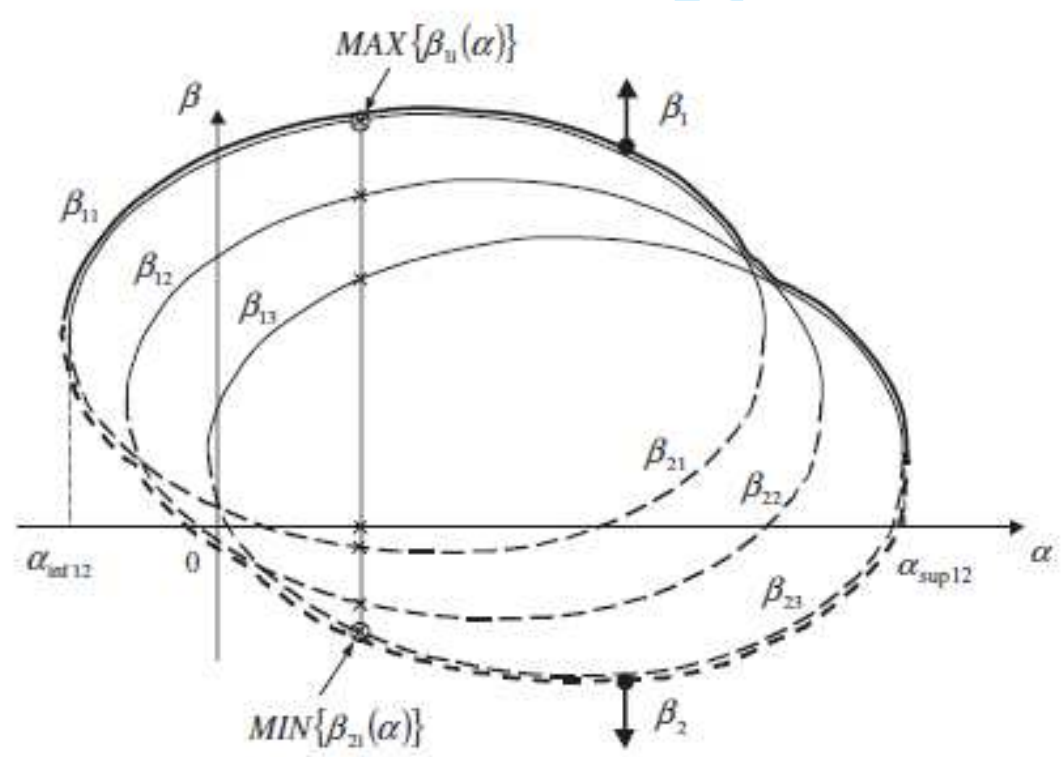

Figure 6. Construction of bounding curves for $\mathrm{Y}_{\mathrm{i}}(\alpha, \beta)<0$ 


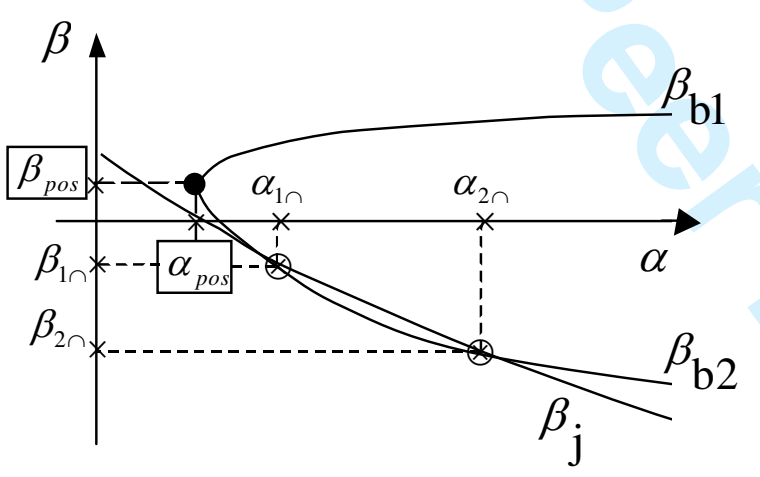

Figure 8a. $\mathrm{j} \in\{2,4\}$

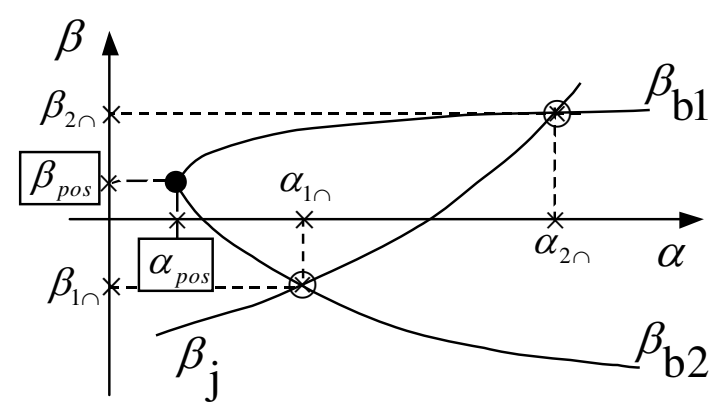

Figure 8c. $j \in\{2,4\}$

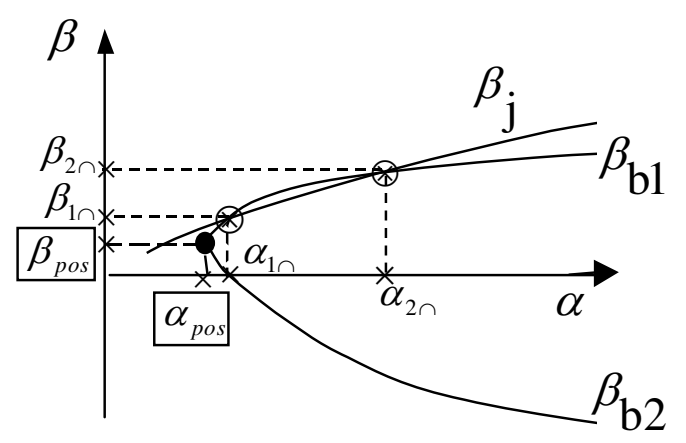

Figure 8b. $\mathrm{j} \in\{1,3\}$

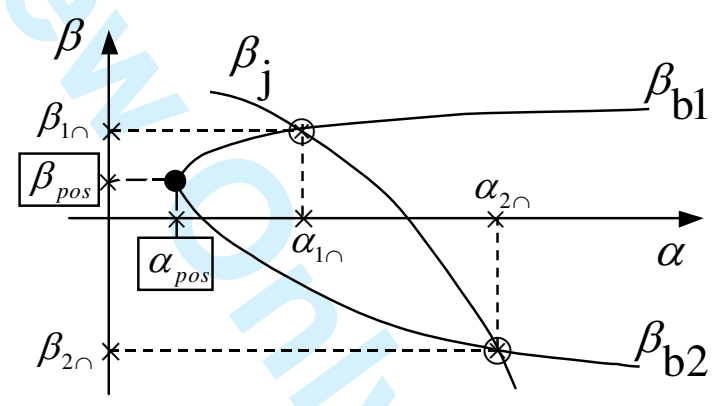

Figure 8d. $\mathrm{j} \in\{1,3\}$

Figure 8. Superimposition of the collision domains 


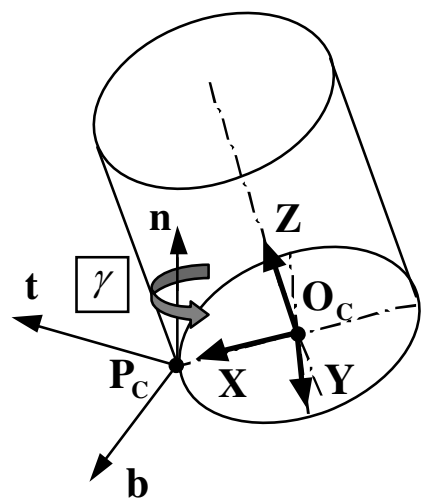

Figure 9. Local reference $\mathfrak{R}_{\mathrm{O}_{4}}$

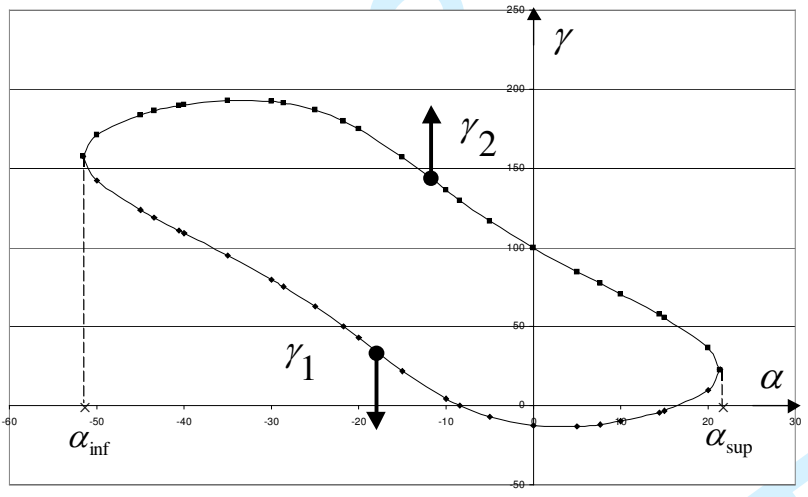

Fig. 10a: Standard curves $\left(Y_{i}<0\right)$

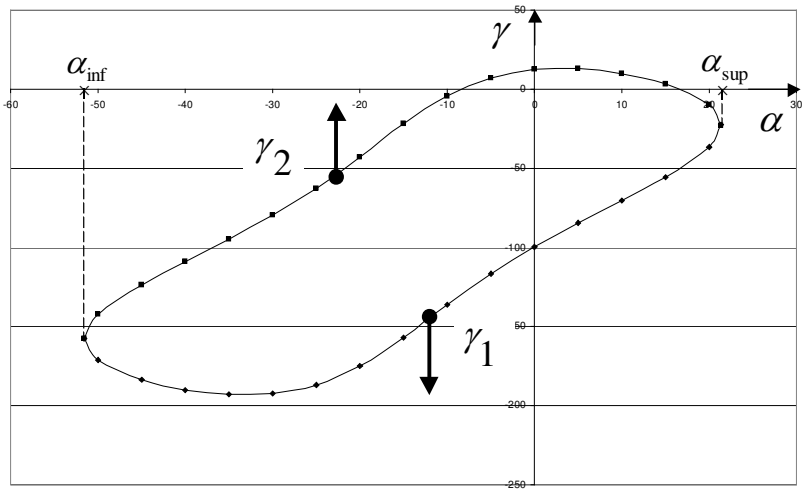

Fig. 10b: Standard curves $\left(Y_{i}>0\right)$

Fig. 10: Standard curves

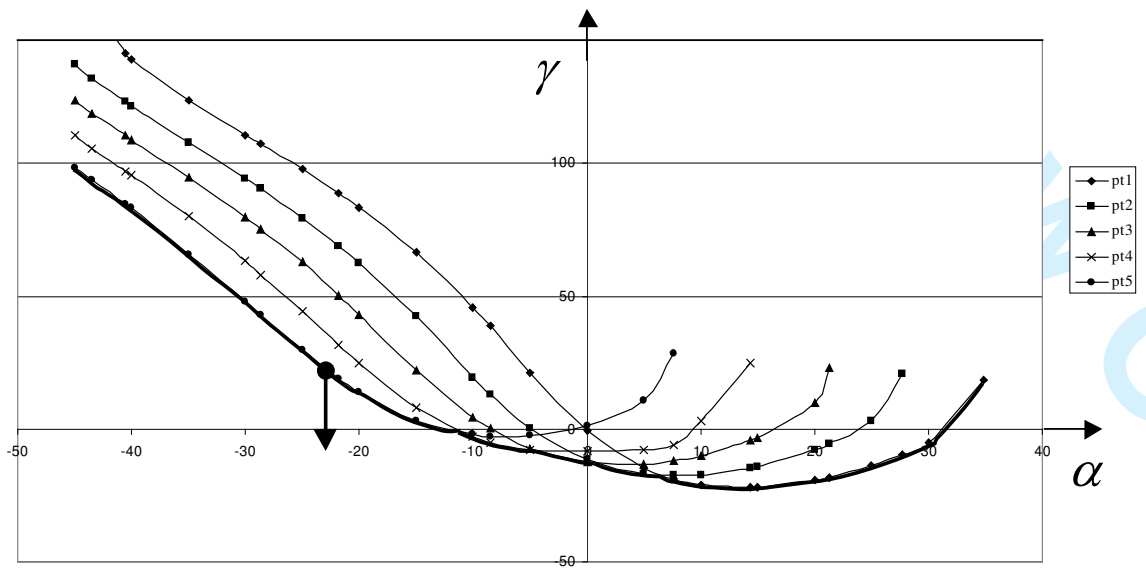

Fig. 11a: Bounding curve for tool disengagement

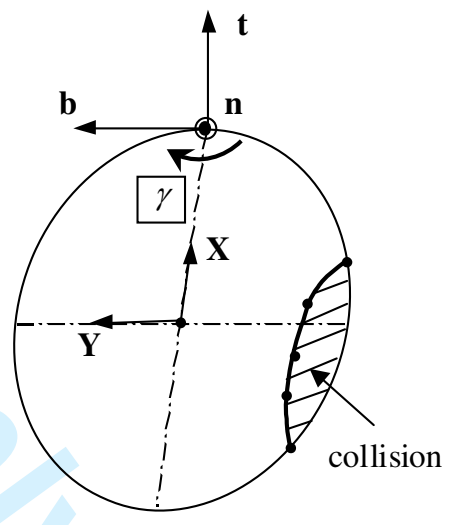

Fig. 11b: Lateral collision Fig. 11: Correction of a low collision 
Figure 12. Partition of the collision domain

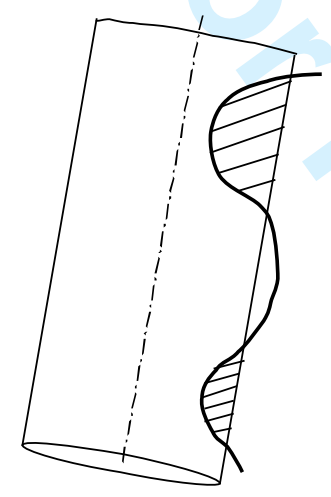

Fig. 13a: $\left(\alpha_{\text {pos }}, \beta_{\text {pos }}\right)$

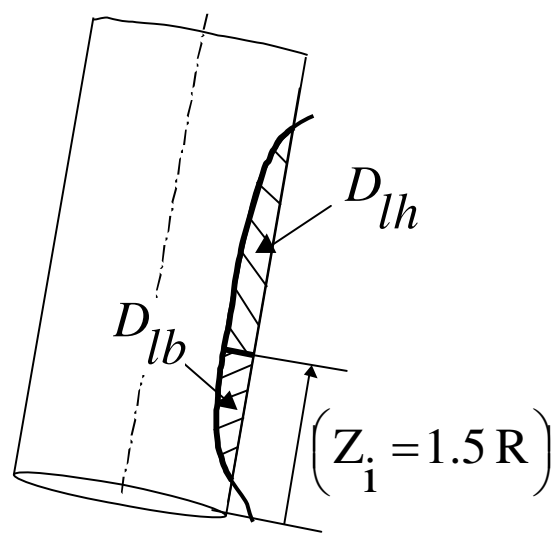

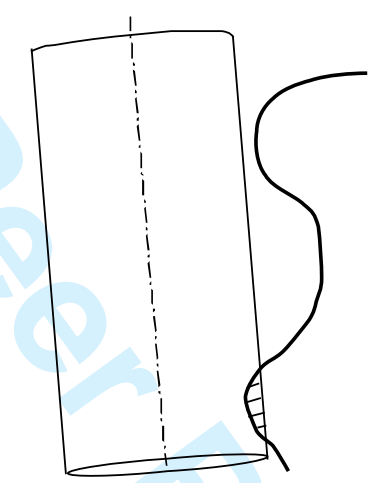

Fig. 13b: $\left(\alpha_{c o r}, \beta_{\text {cor }}\right)$

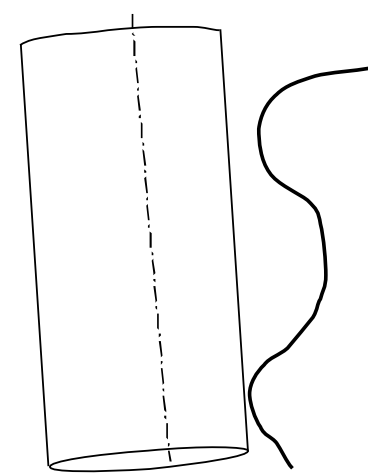

Fig. 13c: $\left(\alpha, \beta_{c o r}, \gamma\right)$

Figure 13. Correction of the cutter 

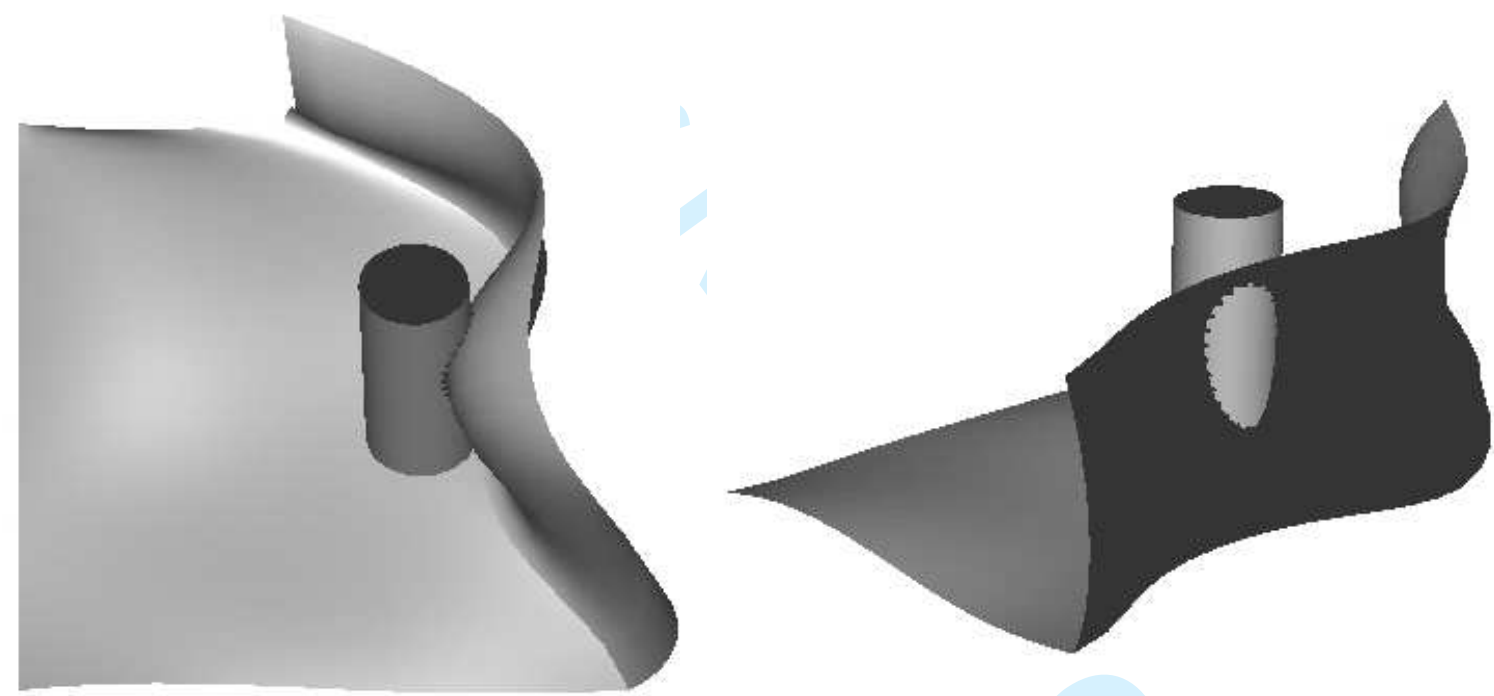

Figure 15. Lateral collision

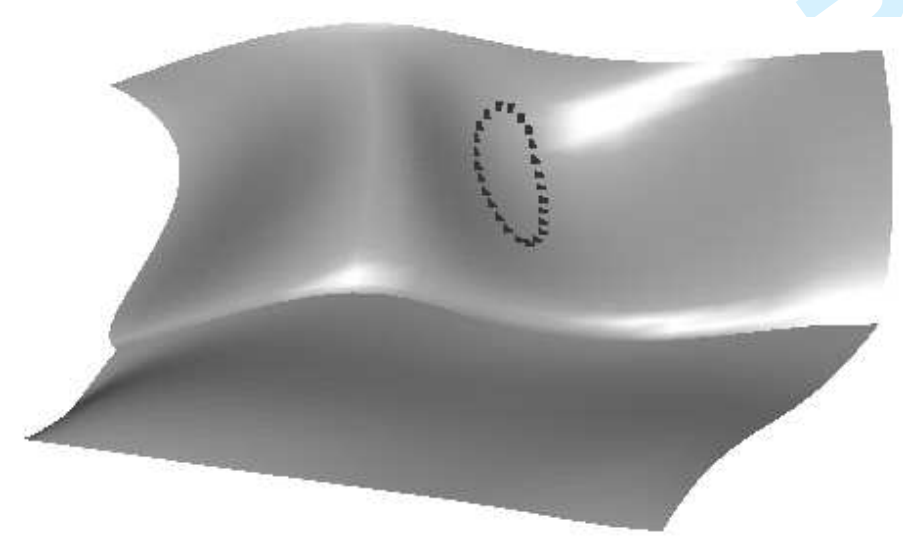

Figure 16. Bounding points of the global collision domain 


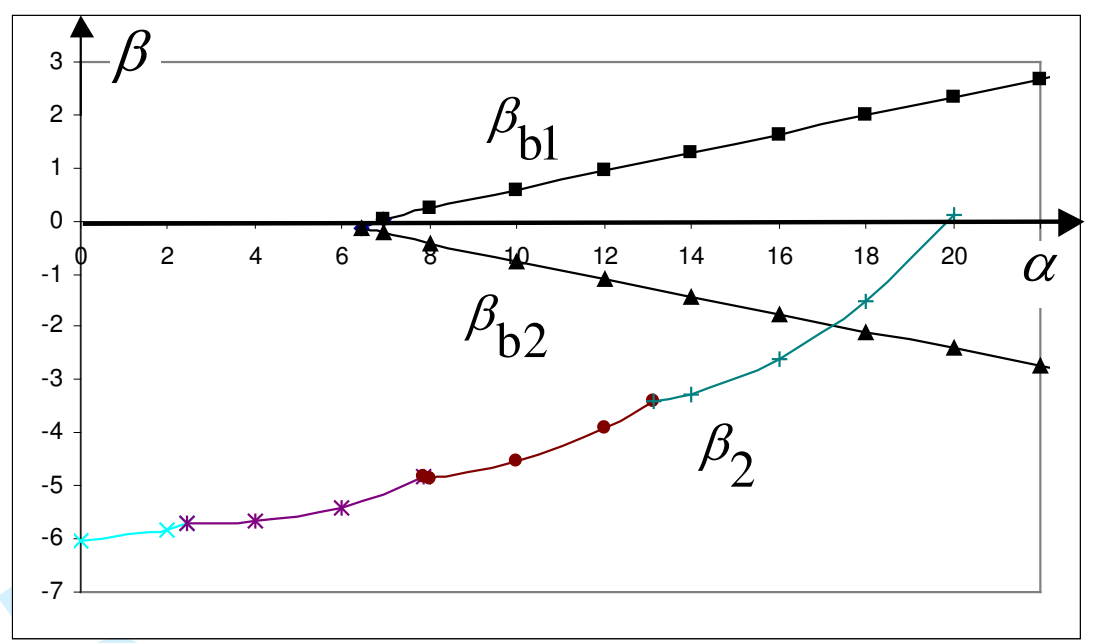

Figure 17. Superimposition of the collision domains

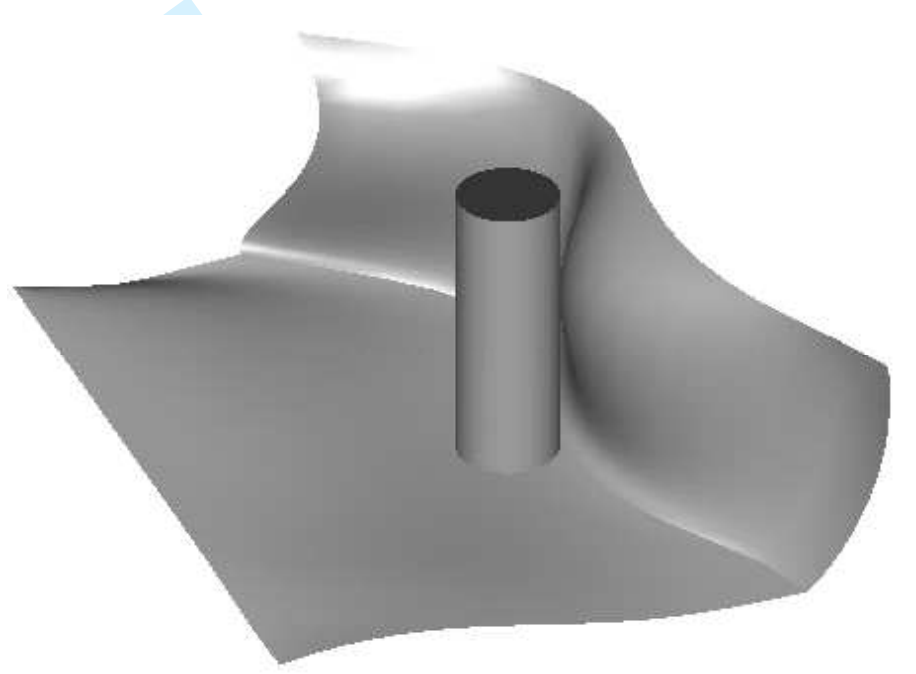

Figure 18. Local and lateral correction of the cutter 


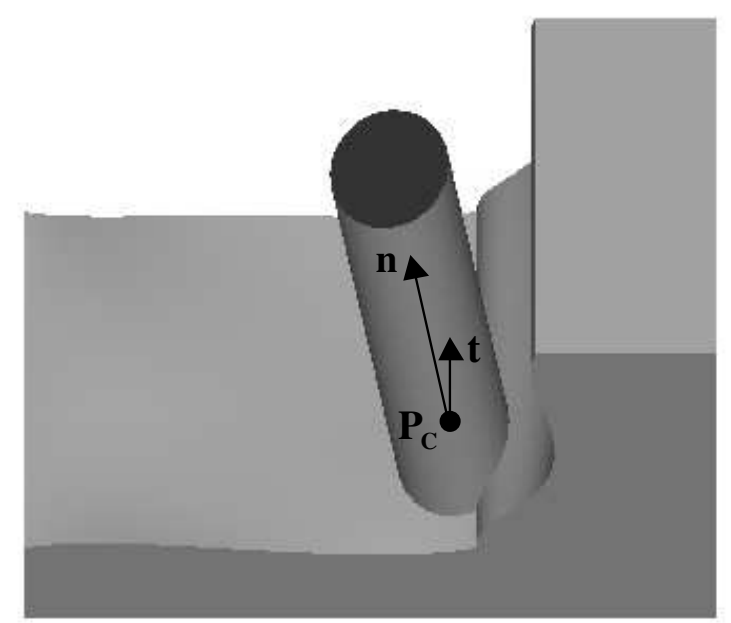

Fig. 19a: Low lateral collision

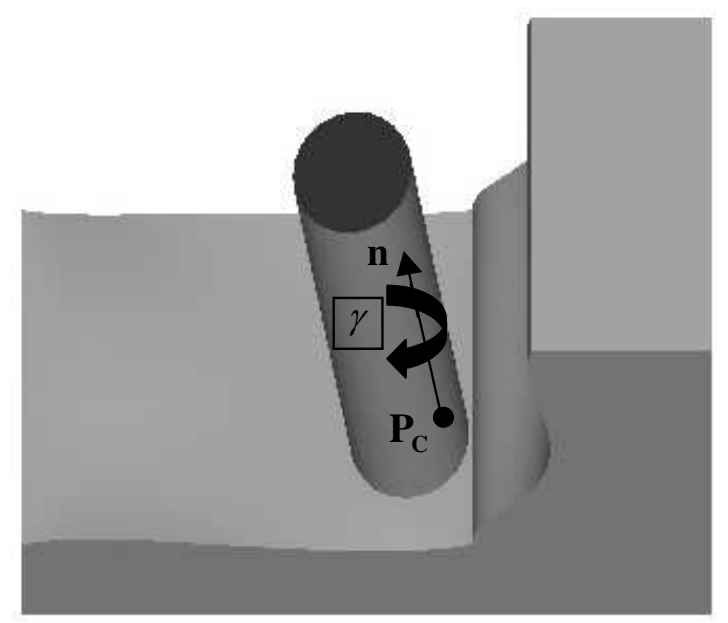

Fig. 19b: Corrected positioning Figure 19. Example of low collision processing

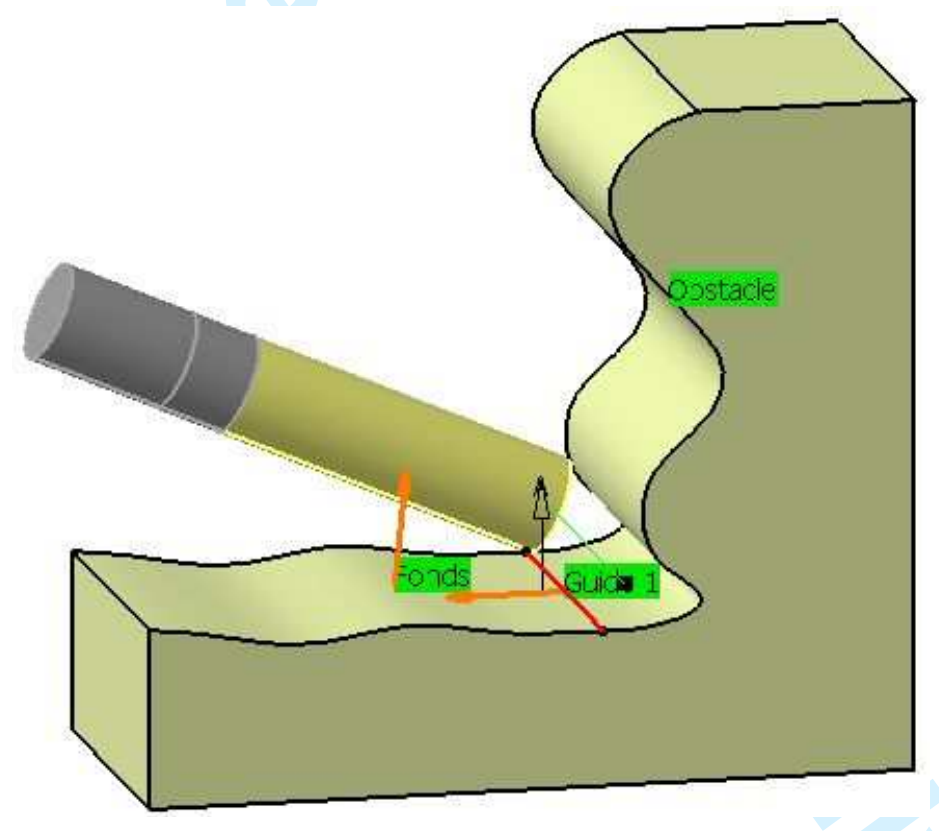

Figure 20. CAM software: $\alpha=0, \beta \in\left[-70^{\circ}, 70^{\circ}\right]$; angular positioning parameters : $\left(\alpha=0, \beta=65,9^{\circ}\right)$ 


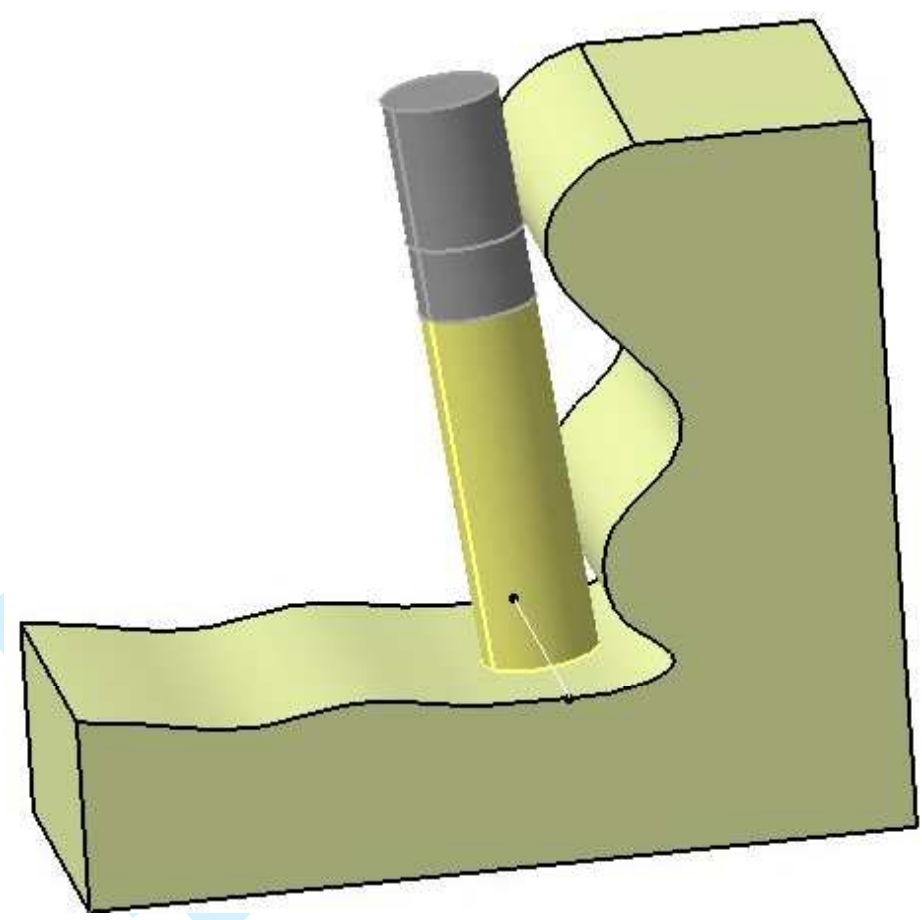

Figure 21. Corrected positioning $\left(\alpha=0.78^{\circ}, \beta=4,63^{\circ}, \gamma=-6.2^{\circ}\right)$ 


\section{TABLE}

\begin{tabular}{|c|c|c|c|c|c|c|}
\hline position & collision & $\alpha_{p o s}$ & $\beta_{p o s}$ & $\alpha_{c o r}$ & $\beta_{c o r}$ & $\mathrm{Z}_{\mathrm{MAX}}$ \\
\hline 1 & - & 3,55 & 0,065 & - & - & - \\
\hline 2 & - & 3,77 & 0,08 & - & - & - \\
\hline 3 & - & 4,21 & 0,077 & - & - & - \\
\hline 4 & - & 4,75 & 0,06 & - & - & - \\
\hline 5 & frontal & 5,41 & 0,045 & 4,55 & $-2,2$ & 0,718 \\
\hline 6 & lateral & 6,1 & 0,015 & 6,1 & $-4,78$ & 1,26 \\
\hline 7 & lateral & 6,52 & $-0,027$ & 6,52 & $-5,93$ & 1,505 \\
\hline 8 & lateral & 6,5 & $-0,07$ & 6,5 & $-6,32$ & 1,54 \\
\hline 9 & lateral & 6,45 & $-0,15$ & 6,45 & $-6,04$ & 1,35 \\
\hline 10 & lateral & 6,13 & $-0,2$ & 6,13 & $-4,83$ & 0,937 \\
\hline 11 & rear & 5,58 & $-0,19$ & 8,96 & $-0,013$ & - \\
\hline 12 & - & 4,68 & $-0,093$ & - & - & - \\
\hline 13 & - & 4,25 & $-0,013$ & - & - & - \\
\hline 14 & - & 4,355 & 0,064 & - & - & - \\
\hline 15 & frontal & 5,66 & 0,319 & $-0,785$ & 1,834 & 1,189 \\
\hline
\end{tabular}

Table 1. Description of position settings 